\title{
Diversity, Relative Abundance, and Functional Genes of Intestinal Microbiota of Tiger Grouper (Epinephelus fuscoguttatus) and Asian Seabass (Lates calcarifer) Reared in A Semi-Closed Hatchery in Dry and Wet Seasons
}

\author{
Jumria Sutra ${ }^{1}$, Hamidu Saadu ${ }^{2}$, Amalia Mohd. Hashim ${ }^{3}$, Mohd Zamri Saad ${ }^{1,4}$, \\ Ina Salwany Md Yasin ${ }^{1,5}$ and Mohammad Noor Azmai Amal ${ }^{1,2 *}$
}

${ }^{1}$ Laboratory of Aquatic Animal Health and Therapeutics, Institute of Bioscience, Universiti Putra Malaysia, 43400 UPM Serdang, Selangor, Malaysia

${ }^{2}$ Department of Biology, Faculty of Science, Universiti Putra Malaysia, 43400 UPM Serdang,

Selangor, Malaysia

${ }^{3}$ Department of Microbiology, Faculty of Biotechnology and Biomolecular Sciences,

Universiti Putra Malaysia, 43400 UPM Serdang, Selangor, Malaysia

${ }^{4}$ Department of Veterinary Laboratory Diagnosis, Faculty of Veterinary Medicine,

Universiti Putra Malaysia, 43400 UPM Serdang, Selangor, Malaysia

${ }^{5}$ Department of Aquaculture, Faculty of Agriculture, Universiti Putra Malaysia, 43400 UPM Serdang,

Selangor, Malaysia

\begin{abstract}
Grouper and Asian seabass are among the economically important cultured marine fish in Malaysia. However, fry productions in large scale tend to introduce stress that changes the fish microbiota and increases susceptibility to diseases. Currently, high-

ARTICLE INFO

\section{Article history:}

Received: 1 November 2020

Accepted: 22 January 2021

Published: 28 May 2021

DOI: https://doi.org/10.47836/pjtas.44.2.06

E-mail addresses:

jumriasutra@gmail.com (Jumria Sutra)

manfashi2006@yahoo.com (Hamidu Saadu) amalia@upm.edu.my (Amalia Mohd. Hashim)

mzamri58@gmail.com (Mohd Zamri Saad)

salwany@upm.edu.my (Ina Salwany Md Yasin)

mnamal@upm.edu.my (Mohammad Noor Azmai Amal)

*Corresponding author

throughput sequencing is used to study fish microbiota and their respective gene functions. In this study, the diversity, abundance and functional genes of intestinal microbiota of tiger grouper and Asian seabass that were reared in a semi-closed hatchery during dry and wet seasons. Intestinal samples were collected from tiger grouper and Asian seabass of different sizes before proceeded to DNA extraction. The extracted DNA were then subjected
\end{abstract}


to $16 \mathrm{~S}$ rRNA gene amplicon sequencing using the Illumina Miseq platform targeting $\mathrm{V} 3$ and V4 regions for determination of the bacterial diversity, abundance and functional genes in both seasons were investigated. The results revealed that intestinal microbiota of Asian seabass were dominated by the phylum Proteobacteria and order Vibrionales in both seasons. Meanwhile, intestinal microbiome of tiger groupers were shifted from domination of phylum Firmicutes and order Clostridiales in dry season to Proteobacteria and order Lactobacillales in wet season. PICRUSt analysis revealed that the functional genes that were dominantly present were the genes encoded for metabolism, genetic information processing, environmental information processing, cellular process and human diseases. Remarkably, SIMPER analysis showed several potential metagenomics biomarker genes in dry and wet seasons. This study revealed the importance of utilizing amplicon metagenomics approaches in microbiome studies for better identification of the microbial profiling in aquaculture systems.

Keywords: Asian seabass, marine fish hatchery, metagenomics, tiger grouper

\section{INTRODUCTION}

Aquaculture has developed rapidly to become one of the most important food industries in the world (Little et al., 2016). In recent years, increased demands from local and export markets for high-value fish species, such as groupers (Epinephelus spp.), Asian seabass (Lates calcarifer), and snapper (Lutjanus spp.) have encouraged hatcheries to produce more fry (Othman et al., 2017). The increasing trend towards developing large-scale production has led to intensive marine aquaculture practices and enhancing vulnerability of fish to disease outbreaks that affects fry production and quality (Ahmad et al., 2019; Ismail et al., 2017; Tarnecki et al., 2017).

A metagenomics study in aquaculture helps to identify pathogens before they cause disease outbreaks in marine fish hatcheries (Martínez-Porchas \& Vargas-Albores, 2017). Furthermore, metagenomic analysis has expanded our knowledge by revealing enormous microbial communities, and some unknown microbial diversity, in a variety of environments (Debroas et al., 2009; Hewson et al., 2009). Within the marine fish hatchery ecosystem, the gastrointestinal tract of fish and the holding water possess hugely diversified microbial communities that vary depending on the fish species (Di Maiuta et al., 2013; Wu et al., 2010). They are considered the main potential sources of infection for many fish pathogens (Barkham et al., 2019; Givens et al., 2015; Roeselers et al., 2011). Moreover, studies have indicated that microbial communities are largely influenced by the environmental factors, such as water salinity, seasons, and geographical area surrounding the host (Amal et al., 2010; Dehler et al., 2017a, 2017b; M. Zhang et al., 2016; Wu et al., 2012). 
Numerous attempts were made to explore the bacterial microbiome within the fish hatchery ecosystem using the culture-based method. Unfortunately, this method has limitations, as only $<10 \%$ of the bacteria could be isolated and cultured under laboratory conditions (Lyons et al., 2015; Tarnecki et al., 2017). On the other hand, next-generation sequencing (NGS) platforms could explore the microbiome communities on unprecedented scale, and allowed identification of both culturable and unculturable bacterial communities within the marine fish hatchery (Wang et al., 2018).

There is scarce information on the effects of seasonal factors on microbiome and metagenome within the tropical marine fish hatchery. Thus, the present study aimed to compare the diversity, relative abundance, and functional genes of intestinal microbiota of tiger grouper and Asian seabass that were cultured in a semi-closed tropical marine fish hatchery in dry and wet seasons.

\section{MATERIALS AND METHODS}

\section{Study Site}

This study was carried out in a semi-closed tropical marine fish hatchery producing tiger grouper (Epinephelus fuscoguttatus) and Asian seabass (Lates calcarifer) fry. This hatchery was located nearby the sea at the east coast of Peninsular Malaysia (5.8290 $\mathrm{N}, 102.5524^{\circ} \mathrm{E}$ ). It was defined as a semiclosed system because the water supply was directly obtained from the nearby open sea throughout the year, was filtered, treated, and aerated before being channelled into the hatchery. Thus, the water quality in the hatchery is influenced by dry and wet seasons.

\section{Fish Samples}

Duplicate samples of fish were collected during the dry (July 2018) and wet (November 2018) seasons. One-time random sampling was made in each season involving various sizes and production batches of tiger groupers $(n=9)$ and Asian seabass $(n=10-13)$.

The sampled tiger groupers and Asian seabass were sedated with tricaine methanesulphonate (MS-222; $50 \mathrm{mg} / \mathrm{L}$ ) before the total body length and weight of each fish were recorded (Table 1). Immediately, the dissections were performed in a sterile condition, where the intestinal samples of respective fish species were pooled and stored in a sterile falcon tube containing $20 \mathrm{~mL}$ of RNAlater ${ }^{\mathrm{TM}}$ solution (Thermo Fisher Scientific, MA, USA) for subsequent DNA analysis. All intestinal samples were kept on ice, transported back to the laboratory, and stored at $-80^{\circ} \mathrm{C}$ until further analysis. The fishes were sampled, handled, and sacrificed according to the methods approved by Institutional Animal Care and Use Committee, Universiti Putra Malaysia.

\section{Water Physicochemical and Seasonal Parameters}

During each sampling, the water physicochemical parameters such as $\mathrm{pH}$, dissolved oxygen (DO), total dissolved solid (TDS), water temperature (T), conductivity (C), salinity (S), ammonia-nitrogen $\left(\mathrm{NH}_{3}-\mathrm{N}\right)$, 
Table 1

Summary of collected fish and water samples for dry and wet seasons

\begin{tabular}{|c|c|c|c|c|c|}
\hline Season & Fish species & $\begin{array}{c}\text { Samples code } \\
\text { (pooled samples) }\end{array}$ & $\begin{array}{c}\text { Number of } \\
\text { fish }\end{array}$ & $\begin{array}{c}\text { Length } \\
\text { Mean } \pm \mathrm{SD} \\
(\mathrm{cm})\end{array}$ & $\begin{array}{c}\text { Weight } \\
\text { Mean } \pm \text { SD }(g)\end{array}$ \\
\hline \multirow[t]{4}{*}{ Dry } & \multirow[t]{2}{*}{$\begin{array}{l}\text { Tiger } \\
\text { grouper }\end{array}$} & DTG1 & 5 & \multirow[t]{2}{*}{$16.37 \pm 5.46$} & \multirow[t]{2}{*}{$54.00 \pm 44.03$} \\
\hline & & DTG2 & 4 & & \\
\hline & \multirow{2}{*}{$\begin{array}{c}\text { Asian } \\
\text { seabass }\end{array}$} & DAS1 & 5 & \multirow[t]{2}{*}{$14.27 \pm 4.45$} & \multirow[t]{2}{*}{$41.93 \pm 35.12$} \\
\hline & & DAS2 & 5 & & \\
\hline \multirow[t]{4}{*}{ Wet } & \multirow{2}{*}{$\begin{array}{l}\text { Tiger } \\
\text { grouper }\end{array}$} & WTG1 & 5 & \multirow[t]{2}{*}{$20.86 \pm 8.73$} & \multirow{2}{*}{$\begin{array}{c}133.43 \pm \\
158.15\end{array}$} \\
\hline & & WTG2 & 4 & & \\
\hline & \multirow{2}{*}{$\begin{array}{c}\text { Asian } \\
\text { seabass }\end{array}$} & WAS1 & 7 & \multirow[t]{2}{*}{$16.13 \pm 6.83$} & \multirow[t]{2}{*}{$60.45 \pm 55.07$} \\
\hline & & WAS2 & 6 & & \\
\hline
\end{tabular}

Note. DTG1 and DTG2 are intestinal samples from tiger grouper for dry season; DAS1 and DAS2 are intestinal samples from Asian seabass for dry season; WTG1 and WTG2 are intestinal samples from tiger grouper for wet season; WAS1 and WAS2 are intestinal samples from Asian seabass for wet season

nitrite $\left(\mathrm{NO}_{2}{ }^{-}\right)$, nitrate $\left(\mathrm{NO}_{3}{ }^{-}\right)$, phosphate $\left(\mathrm{PO}_{4}{ }^{3-}\right)$, and sulphate $\left(\mathrm{SO}_{4}{ }^{2-}\right)$ were measured and recorded accordingly either by using YSI 556 MPS probe (YSI Incorporated, NY, USA) or DR900 spectrophotometer (Hach Company, Loveland, USA). Parameters for the respective season, such as average rainfall (AR), average temperature (AT), and average humidity $(\mathrm{AH})$ were obtained from the Malaysian Meteorological Department, Ministry of Energy, Science, Technology, Environment and Climate Change, Malaysia.

\section{Isolation of Genomic DNA}

All intestinal samples were thawed at room temperature before being washed with sterile phosphate buffered saline solution (PBS; $10 \mathrm{mM}$ sodium phosphate, $150 \mathrm{mM}$ sodium chloride, $\mathrm{pH}$ 7.2) thrice.
The genomic DNA was extracted using Favorprep ${ }^{\mathrm{TM}}$ Stool DNA Isolation Mini Kit (Favorgen Biotech Corporation, Changzhi, Taiwan), according to the manufacturer's instructions, with additional treatment of RNase A.

Replicates of genomic DNA of tiger groupers and Asian seabass were prepared. The quantity and purity for the extracted DNA were tested using NanoDrop 2000 UV-Vis Spectrophotometer (Thermo Fisher Scientific, MA, USA) in $1 \%$ agarose gel. All the extracted DNA was stored at $-80^{\circ} \mathrm{C}$ until further processing.

\section{High-Throughput Miseq Illumina Sequencing Platform}

Eight DNA samples, consisting of four DNA samples from each dry and wet 
season (two from tiger grouper and two from Asian seabass) were sent for sequencing to Novogene Biological Information Technology Co. (Tianjin, China), through Apical Scientific Sdn. Bhd. (Seri Kembangan, Malaysia). The V3-V4 region of $16 \mathrm{~S}$ rRNA was amplified using 16S rRNA gene PCR primers for classical and next-generation sequencing-based diversity studies, and the Illumina adapter overhang nucleotide were added to gene specific sequences (Klindworth et al., 2013). The 16S rRNA amplicon PCR forward and reverse primers were as follows:

Forward-(5'-TCGTCGGCAGTGTGTATA AGAGACAGCCTACGGGNGGCWGCA G -3'); reverse - (5' -TCTCGTGGGCT CGGAGATGTGTATAAGAGACAGG ACTACHVGGGTATCTAATC - 3'). The 16S rRNA amplicon sequencing was done through the Illumina Miseq (San Diego, California, U.S.A) platform, resulting in the $250 \mathrm{bp}$ paired-end reads.

\section{S rRNA Amplicon Sequencing Data Analysis}

Paired-end sequences were obtained in .fastq format for all samples. All sequences were further trimmed to remove primer and barcoded sequences using Pairedend adapter trimming (PEAT) (Magoč \& Salzberg, 2011). Fastq files were imported into Quantitative Insight into Microbial Ecology (QIIME) software (v1.7.0), and merged accordingly to each respective sample using PEAR (Zhang et al., 2013). The merged sequences were filtered using the fastq_quality_filter script under the fastx_toolkit with $q=20$ and $p=70$. Chimeric sequences were screened, using UCHIME against the RDP_GOLD v9 database and were removed from the downstream processing (Haas et al., 2011). Sequences shorter than $100 \mathrm{bp}$ or longer than 600 bp were removed along with low quality bases $(\mathrm{Q} \leq 33)$.

Operational taxonomic units (OTUs) were selected with $\geq 97 \%$ similarity using the pick_otus.py script with the usearch_ref method against the Greengenes database (Edgar et al., 2011). OTU table was constructed and validated following the OTU picking. Alpha diversity metrics were calculated at the same sequence depth of minimum reads for observed species, Chao1, and community diversity indices (Shannon and Simpson). Association of OTU for each dry and wet season were displayed by using Venn diagram which were constructed by using $\mathrm{R}$ software on "ggplot" packages. Bray-Curtis distant assessment was also measured to estimate the beta diversity for each season (Bray \& Curtis, 1957). The computation of BrayCurtis and PERMANOVA test were done with Paleontological Statistics (PAST) software (v3.11) (Hammer et al., 2001). The Bray-Curtis estimated distances were used to plot principal coordinates analysis (PCoA). Microorganisms that were specifically associated with each sample were characterised using the Linear discriminant analysis effect size (LEfSe), which measured both biological relevance and statistical significance (Segata et al., 2011). 


\section{Metagenome Prediction of 16S rRNA Datasets}

Functional prediction from the 16S rRNA datasets for all samples were conducted using Phylogenetic Investigation of Communities by Reconstruction of Unobserved States (PICRUSt) software (Langille et al., 2013) in the Galaxy server. OTU abundances, resulting against the Greengenes database, act as the input file in BIOM formatted for PICRUSt (v1.1.0). The input file was uploaded into Galaxy Langille Lab (Langille et al., 2013) for 16S rRNA gene copy number normalisation using the normalize_by_copy_number.py script followed by metagenome prediction using the predict_metagenomes.py script, against the KEGG Orthology (KO) database. Similarity Percentage analysis (SIMPER) was conducted to choose top 10 genes that showed higher differential average contributions towards each season. All predicted metagenomes were categorised by their functions using categorize_by_ function.py script and collapsed respectively into the level 1 and level 2 gene pathways. The metagenome contribution of taxa to different KEGG Orthologs (KOs) were computed to see the related taxa that contribute to differentiation between dry and wet season using metagenome_contribution. py.

\section{Data Analysis}

All environmental parameters consist of physicochemical and seasonal parameters were subjected to Shapiro-Wilk for normality distribution test before t-tests analysis using
IBM SPSS (Version 21.0, IBM Corporation, Chicago, IL, USA) to test for significance difference between dry and wet seasons. Alpha diversity indices matrices were also subjected for fitness to a normal distribution by Shapiro-Wilk test and followed with t-test analysis by using IBM SPSS (Version 21.0, IBM Corporation, Chicago, IL, USA) to tests for a significant difference between dry and wet season. Statistical significance was determined at $\mathrm{p}<0.05$.

\section{Data Availability}

The 16S rRNA datasets were deposited in the NCBI Sequence Read Archive database under the following BioProject: PRJNA602621 with accession numbers of SRX7616297, SRX7616296, SRX7616295, SRX7616294, SRX7616291, SRX7616290, SRX7616287, and SRX7616286.

\section{RESULTS}

\section{Fish and Water Quality Analysis}

The average length and weight of tiger grouper and Asian seabass that were collected during the study period are presented in Table 1. The T, S, TDS, C, $\mathrm{NH}_{3}-\mathrm{N}, \mathrm{NO}_{3}^{-}, \mathrm{NO}_{2}^{-}$, and $\mathrm{SO}_{4}{ }^{2-}$ were among the physicochemical parameters that showed significant differences $(\mathrm{p}<0.05)$ between the dry and wet seasons (Table 2). Other than that, seasonal parameters such as AR and AT also showed significant differences $(\mathrm{p}<0.05)$ between the seasons. Among the 14 environmental parameters that were measured, a total of 10 parameters showed significant differences $(p<0.05)$ between both seasons in this hatchery. 
Table 2

Environmental parameters of water samples between dry and wet seasons

\begin{tabular}{|c|c|c|}
\hline Seasons & Dry & Wet \\
\hline $\mathrm{T}\left({ }^{\circ} \mathrm{C}\right)^{*}$ & $30.77 \pm 0.06$ & $29.57 \pm 0.11$ \\
\hline $\mathrm{pH}(1-14)$ & $7.59 \pm 0.13$ & $7.46 \pm 0.18$ \\
\hline$S(p p t)^{*}$ & $27.53 \pm 0.03$ & $26.36 \pm 0.06$ \\
\hline DO (mg/L) & $3.84 \pm 0.86$ & $5.57 \pm 0.06$ \\
\hline $\operatorname{TDS}(\mathrm{g} / \mathrm{L})^{*}$ & $27,986.83 \pm 13.53$ & $26,873.33 \pm 47.18$ \\
\hline $\mathrm{C}(\mu \mathrm{s} / \mathrm{cm})^{*}$ & $43,057.00 \pm 21.70$ & $41,341.33 \pm 72.34$ \\
\hline $\mathrm{NH}_{3}-\mathrm{N}(\mathrm{mg} / \mathrm{L})^{*}$ & $0.18 \pm 0.04$ & $0.37 \pm 0.01$ \\
\hline $\mathrm{NO}_{2}^{-}(\mathrm{mg} / \mathrm{L})^{*}$ & $0.01 \pm 0.00$ & $0.04 \pm 0.01$ \\
\hline $\mathrm{NO}_{3}{ }^{-}(\mathrm{mg} / \mathrm{L})^{*}$ & $0.83 \pm 0.06$ & $0.43 \pm 0.06$ \\
\hline $\mathrm{PO}_{4}{ }^{3-}(\mathrm{mg} / \mathrm{L})$ & $0.24 \pm 0.01$ & $0.27 \pm 0.29$ \\
\hline $\mathrm{SO}_{4}^{2-}(\mathrm{mg} / \mathrm{L})^{*}$ & $2,000.00 \pm 0.00$ & $2,500.00 \pm 200.00$ \\
\hline $\operatorname{AR}(\mathrm{mm})^{*}$ & $7.43 \pm 11.50$ & $22.60 \pm 30.80$ \\
\hline $\mathrm{AT}\left({ }^{\circ} \mathrm{C}\right)^{*}$ & $27.90 \pm 0.90$ & $26.40 \pm 1.00$ \\
\hline $\mathrm{AH}(\%)$ & $80.90 \pm 3.40$ & $86.80 \pm 5.20$ \\
\hline
\end{tabular}

Note. T: water temperature; S: salinity; DO: dissolved oxygen; TDS: total dissolved solid; C: water conductivity; $\mathrm{NH}_{3}-\mathrm{N}$ : ammonia-nitrogen; $\mathrm{NO}_{2}{ }^{-}$: nitrite; $\mathrm{NO}_{3}{ }^{-*}$ : nitrate; $\mathrm{PO}_{4}{ }^{3-*}$ : phosphate; $\mathrm{SO}_{4}{ }^{2-*}$ : sulphate; AR: average rainfall; AT: ambient temperature; AH: average humidity. $*$ indicates significant difference $(p<0.05)$ between dry and wet seasons

\section{S rRNA Sequencing Summary}

There were a total of 1,923,874 paired-end reads generated from the Illumina Miseq sequencing. A range of 151,126 - 297,541 clean tags, 124,104 - 280,232 effective tags, and 98,184 - 264,838 taxons tags were obtained across all 16S rRNA gene sequencing samples (Table 3). Based on the $97 \%$ similarity cut off, between 941 and 2,100 operational taxonomic units (OTUs) were recorded in the samples.

Analysis of Bacterial Community Structure and Composition in 16S rRNA Datasets Chao1, Shannon and Simpson diversity values varied from 220.40 1,547.01, $2.73-3.75$, and 0.87 - 0.94, respectively (Table 4A). Generally, alpha diversity indicated that Asian seabass had higher contribution in terms of richness and evenness during dry and wet seasons. In Asian seabass, all indices measure of the intestinal samples during the wet season (WAS) were higher compared to dry season (DAS). Meanwhile, for tiger grouper, obvious differences were shown in observed species and Chaol, where intestinal samples during dry seasons (DTG) showed higher measures compared to the 
wet season (WTG). All diversity metrics showed significant differences $(\mathrm{p}<0.05)$ across Asian seabass and tiger grouper in both seasons (Table 4B). On the other hand, the intestinal samples of tiger grouper from the dry season (DTG) had significantly ( $p$ $<0.05$ ) higher diversity in Chaol than the wet season (WTG), but not for the Simpson measure (Table 4C).

A comparison between dry and wet seasons on beta diversity and composition of bacterial OTUs showed significant differences $(\mathrm{p}<0.05 ; \mathrm{p}=0.0023)$ (PERMANOVA; $\mathrm{F}=3.458, \mathrm{p}=0.001$ ) (Figure 1A). Principal coordination analysis (PCoA) supported the data, as the cluster of dry season was separated further from wet season (Figure 1B).

Relative abundances of top 10 phyla profiles of bacterial OTUs were showed in Figure 2. All samples were dominated by Firmicutes, Proteobacteria, Fusobacteria, Actinobacteria, Plantomycetes, Bacteroidetes, Verrucomicrobia, Cyanobacteria, SBR1093, and Acidobacteria. Both DAS and WAS were represented mainly by the phyla of Proteobacteria (43.45\% and $43.10 \%)$, Firmicutes $(33.51 \%$ and $38.99 \%$ ), and Fusobacteria $(22.71 \%$ and $15.05 \%)$. In contrast, DTG phyla were dominated by Firmicutes (88.34\%), followed by Fusobacteria (17.88\%), and Proteobacteria (5.99\%). Meanwhile in WTG, Proteobacteria (57.33\%) were the most abundant phyla, followed by Firmicutes (32.41\%) and Fusobacteria $(8.83 \%)$.
Clostridiales, Vibrionales, Fusobacteriales, Lactobacillales, Rhodobacterales, Alteromonadales, Aeromonadales, Anthomonadales, Enterobacteriales, and Tericiabacterales were the top 10 order across all samples (Figure 2). DAS was dominated by Vibrionales (41.62\%), followed by Clostridiales (32.33\%) and Fusobacteriales (22.71\%). Meanwhile, WAS was dominated by Rhodobacterales (24.17\%), Lactobacillales (23.20\%) and Vibrionales (16.25\%). For DTG, Clostridiales was dominant at $87.25 \%$, followed by Fusobacteriales (7.06\%) and Vibrionales (3.44\%). In contrast, WTG was mainly presented by Lactobacillales (25.51\%), Vibrionales (19.27\%), and Alteromonadales (13.03\%).

Additionally, LEfSe analysis showed differential taxa in both Asian seabass (AS) and tiger grouper (TG) samples. Figure 3 shows that the intestinal samples of tiger grouper had more specific taxa than the intestinal samples from Asian seabass, which consisted of Xanthomonadales, Enterobacteriaceae, Enterobacteriales and Bacillales with LDA higher than 3.0. Meanwhile, Staphylococcaceae, Pseudomanadaceae, Bukholderiales, Erysipelotrichales, Erysipelotrichaceae, Erysipelotrichi, Sinobacteraceae, Planococcaceae, Comamonadaceae, Oxalobacteraceae, and Enterococcaceae showed LDA score higher than 2.0. In the AS samples, taxa that dominated with LDA score higher than 3.0 were Plantomycetes, Turicibacterales, and Turicibacteraceae. TM7, Synechococcophycideae, 
Diversity, Relative Abundance, and Functional Genes of Microbes

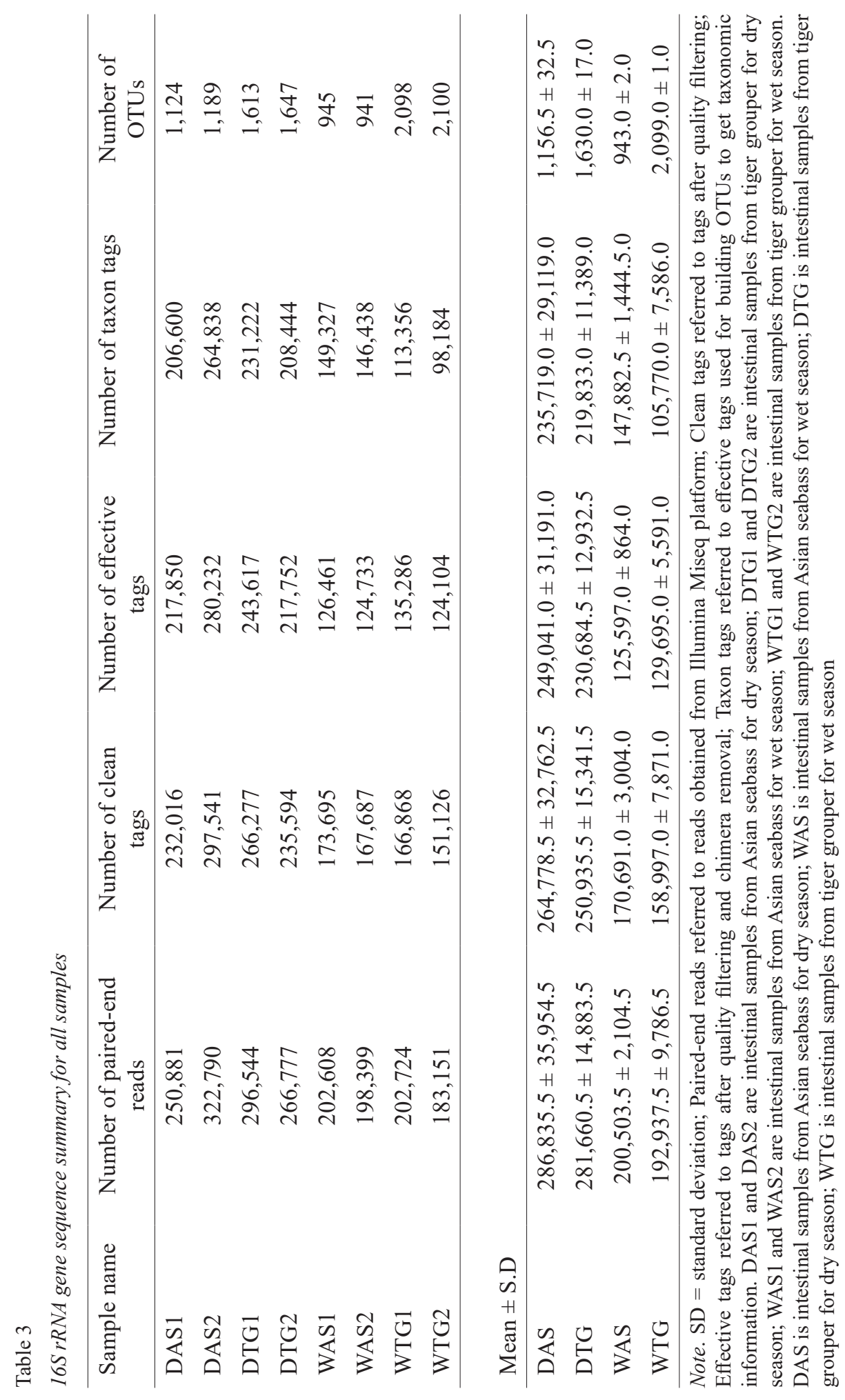


Synechococcales, Synechococcaceae, Phyllobacteriaceae, Plantomycetia, and Plantomycetes were among taxa that has LDA higher than 2.0.

Figure 4 shows the taxa detected between dry and wet season. In TG samples, taxa that mostly present abundantly higher in dry season was only Enterococcaceae, while in wet season, Bacillales, Staphylococcaceae, Planococcaceae, Erysipelotrichi, Erysipelotrichales, Erysipelotrichaceae, Bukholderiales, Comamonadaceae, Enterobacteriales, Oxalobacteraceae,
Enterobacteriaceae, Pseudomanadaceae, Xanthomonadales, and Sinobacteraceae were the most abundance.

For AS samples, taxa Synechococcaceae was the only taxa that showed differential abundant in dry season, meanwhile Synechococcales, Synechococcophycideae, Turicibacterales, Turicibacteraceae, Plantomycetes, Plantomycetia, Phyllobacteriaceae, and TM7 were the differential abundant taxa that present in wet season.

Table 4

Alpha diversity metrics for (A) all samples, (B) Asian seabass and (C) tiger grouper samples between dry and wet seasons

\begin{tabular}{lcccc}
\hline $\begin{array}{l}\text { (A) Sample } \\
\text { name }\end{array}$ & $\begin{array}{c}\text { Observed } \\
\text { species }\end{array}$ & Chao1 & Shannon & Simpson \\
\hline DAS1 & 842 & $1,068.66$ & 2.73 & 0.87 \\
DAS2 & 830 & $1,064.00$ & 2.74 & 0.87 \\
DTG1 & 1,274 & $1,526.82$ & 3.07 & 0.87 \\
DTG2 & 1,283 & $1,547.01$ & 3.09 & 0.89 \\
WAS1 & 703 & 819.06 & 3.73 & 0.94 \\
WAS2 & 683 & 821.78 & 3.75 & 0.94 \\
WTG1 & 203 & 220.40 & 2.80 & 0.90 \\
WTG2 & 216 & 229.54 & 2.85 & 0.91 \\
\hline
\end{tabular}

\begin{tabular}{lcccc}
\hline (B) Sample & $\begin{array}{c}\text { Observed } \\
\text { species* }\end{array}$ & Chao1* & Shannon* & Simpson* \\
\hline DAS & $836.00 \pm 6.00$ & $1,066.30 \pm 2.30$ & $2.73 \pm 0.01$ & $0.87 \pm 0.00$ \\
WAS & $693.00 \pm 10.00$ & $820.40 \pm 1.30$ & $3.74 \pm 0.01$ & $0.94 \pm 0.00$ \\
\hline
\end{tabular}


Table 4 (Continued)

\begin{tabular}{lcccc}
\hline (C)Sample & $\begin{array}{c}\text { Observed } \\
\text { species* }\end{array}$ & Chao1* & Shannon* & Simpson* \\
\hline DTG & $1,278.50 \pm 4.50$ & $1,536.95 \pm 10.10$ & $3.08 \pm 0.01$ & $0.88 \pm 0.01$ \\
WTG & $209.50 \pm 6.50$ & $224.95 \pm 4.60$ & $2.82 \pm 0.03$ & $0.91 \pm 0.00$ \\
\hline
\end{tabular}

Note. DAS1 and DAS2 are intestinal samples from Asian seabass for dry season; DTG1 and DTG2 are intestinal samples from tiger grouper for dry season; WAS1 and WAS2 are intestinal samples from Asian seabass for wet season; WTG1 and WTG2 are intestinal samples from tiger grouper for wet season; DAS is intestinal samples from Asian seabass for dry season; WAS is gut samples from Asian seabass for wet season; DTG is intestinal samples from tiger grouper for dry season; WTG is intestinal samples from tiger grouper for wet season. * indicates significant difference $(p<0.05)$ of the same column only

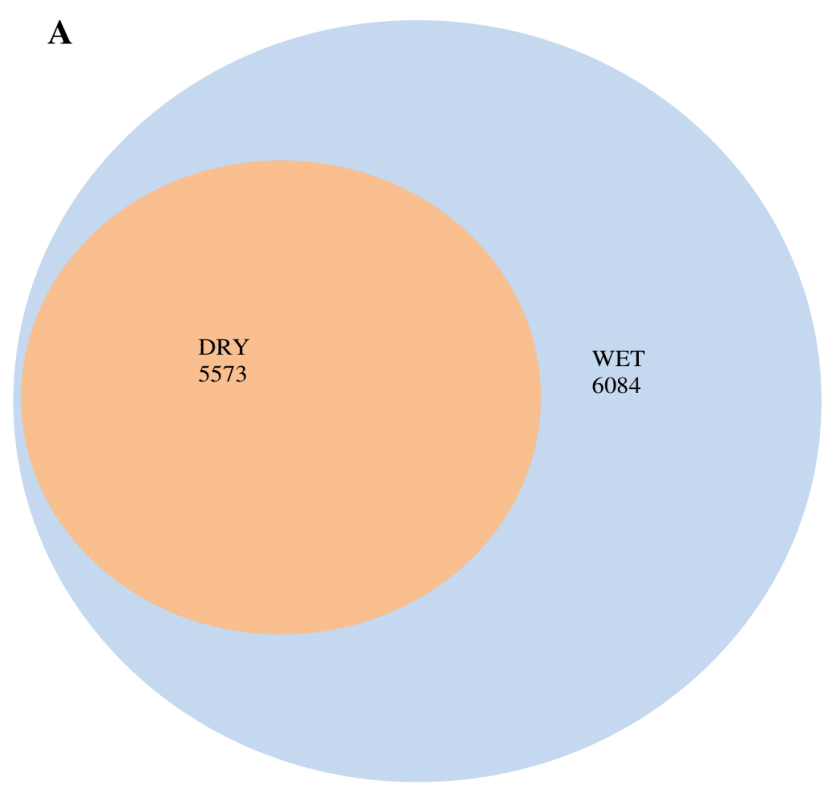

Figure 1. (A) Venn diagram of microbial communities at OTUs level between dry and wet seasons 


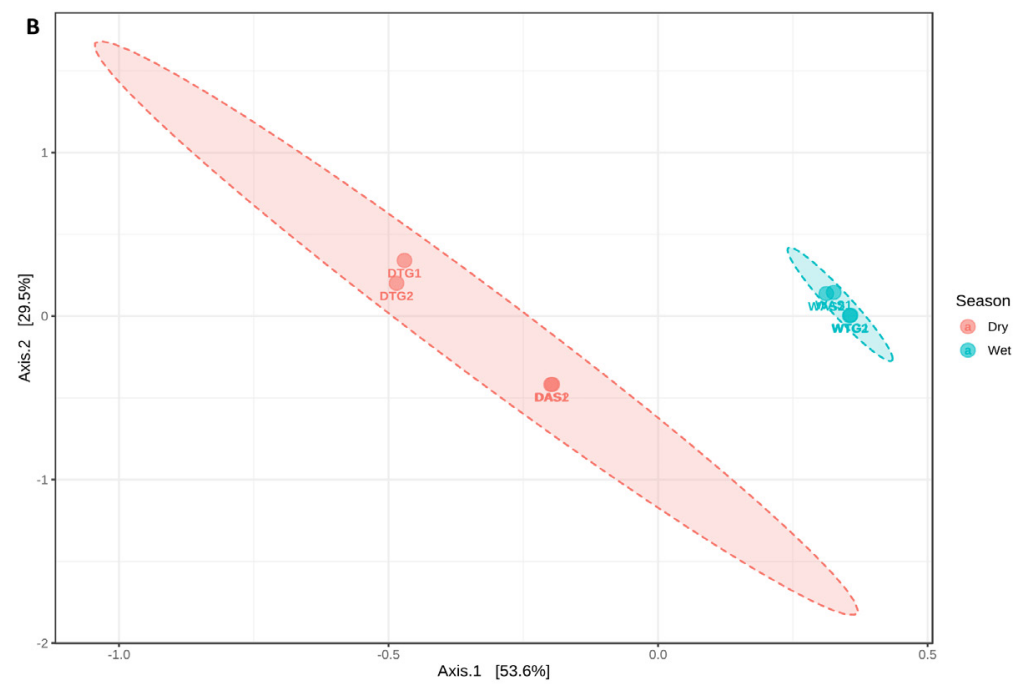

Figure 1(B). Principal coordination analysis ( $\mathrm{PCOA})$ between wet and dry seasons

[Note. DAS1 and DAS2 are intestinal samples from Asian seabass for dry season; DTG1 and DTG2 are intestinal samples from tiger grouper for dry season; DW1 and DW2 are water samples for dry season; WAS1 and WAS2 are intestinal samples from Asian seabass for wet season; WTG1 and WTG2 are intestinal samples from tiger grouper for wet season; WW1 and WW2 are water samples for wet season]

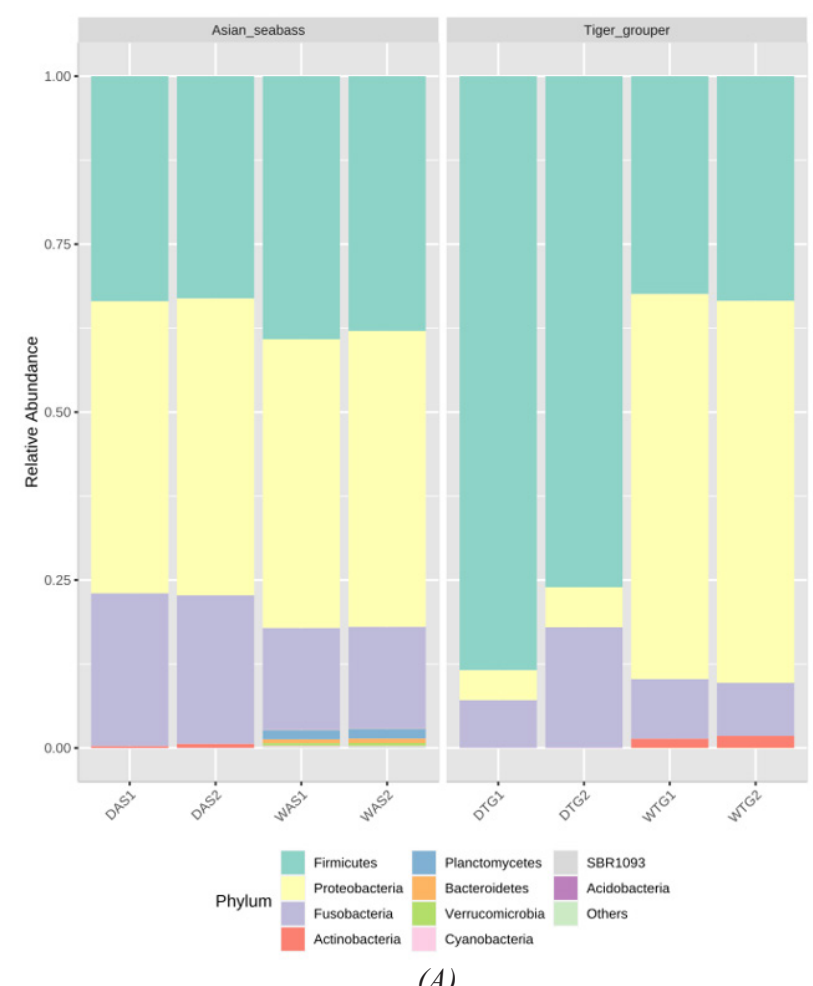




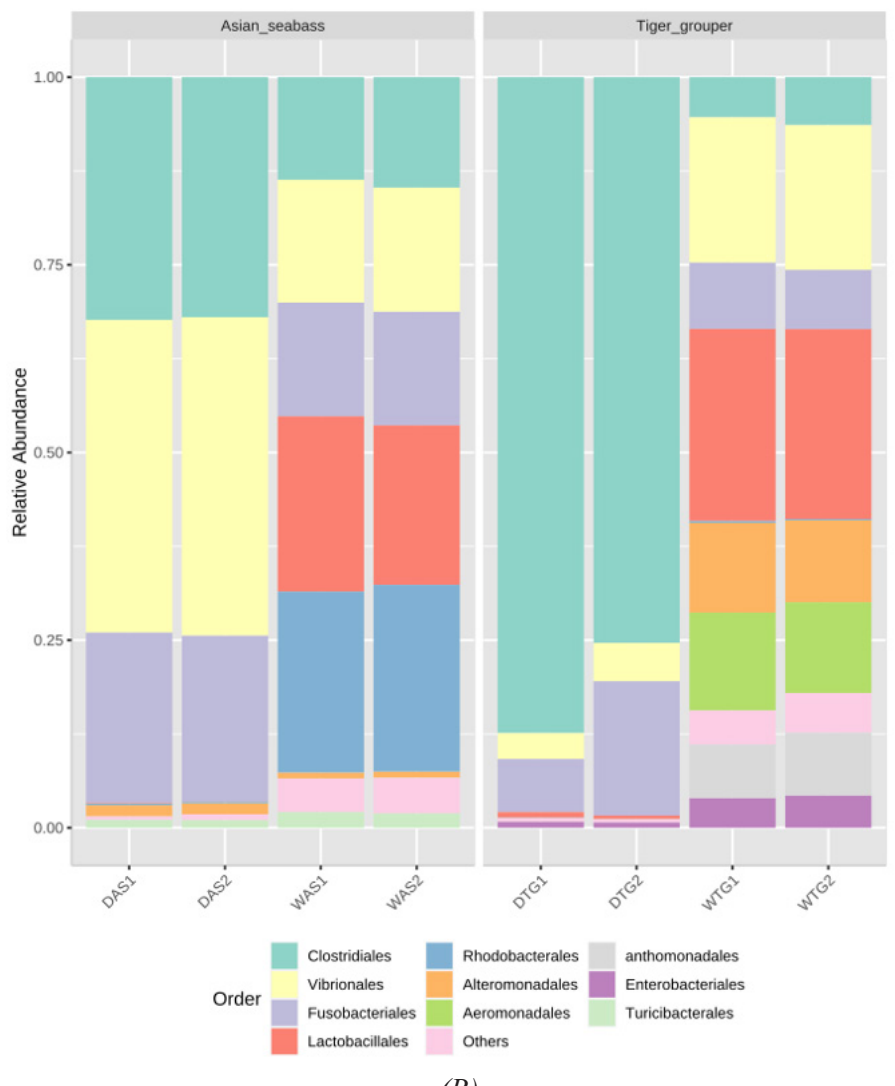

(B)

Figure $2(A) \&(B)$. Relative abundance of dominant phyla, and order in each sample resulting from $16 \mathrm{~S}$ rRNA results between each season

[Note. DAS1 and DAS2 are intestinal samples from Asian seabass for dry season; DTG1 and DTG2 are intestinal samples from tiger grouper for dry season; DW1 and DW2 are water samples for dry season; WAS1 and WAS2 are intestinal samples from Asian seabass for wet season; WTG1 and WTG2 are intestinal samples from tiger grouper for wet season; WW1 and WW2 are water samples for wet season] 
A

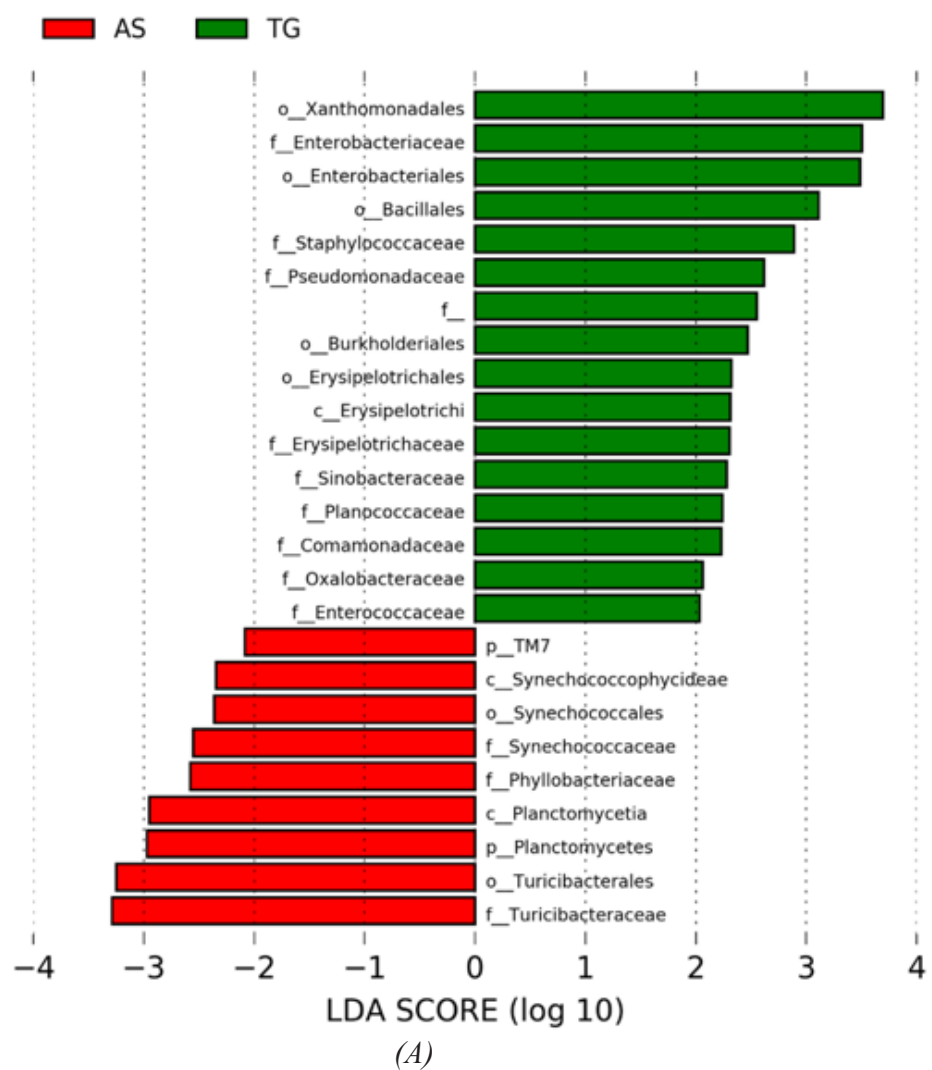

Figure 3(A). Differentially abundant bacterial clades detected by LEfSe showing hierarchical structure of the bacterial clades up to order level

[Note. AS are intestinal samples from Asian seabass; TG are intestinal samples from tiger grouper] 


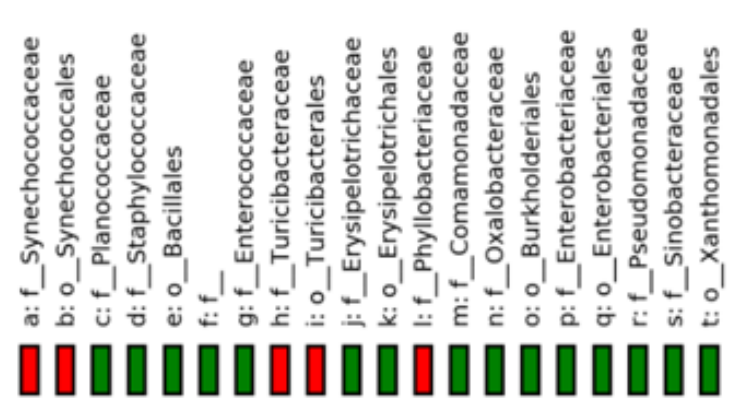




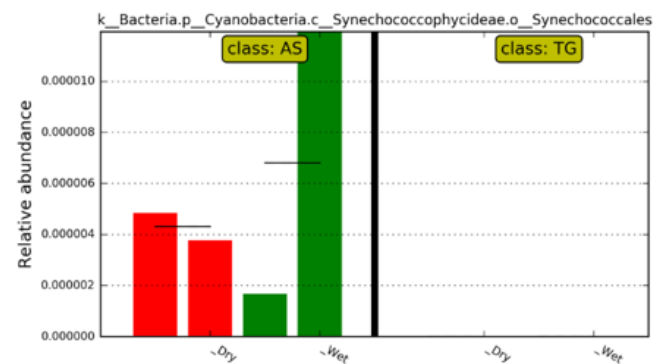

C

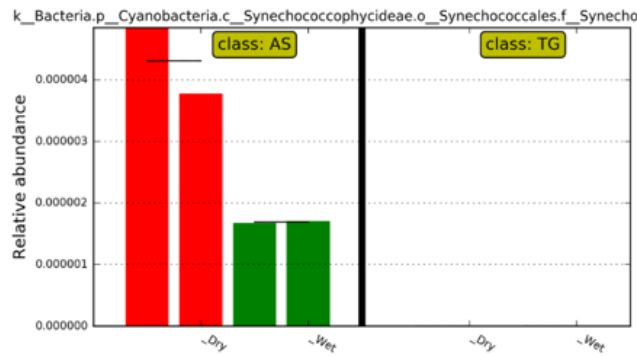

E
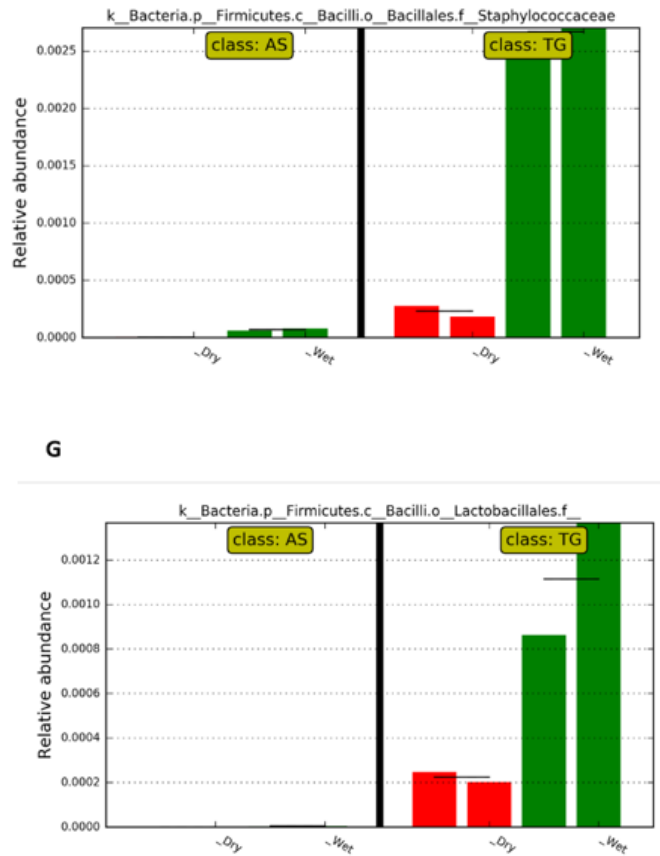

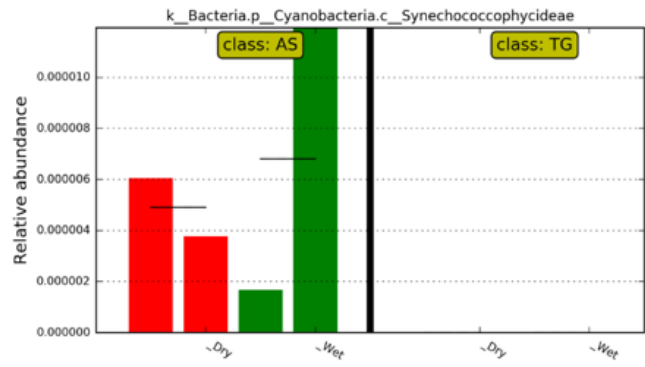

D
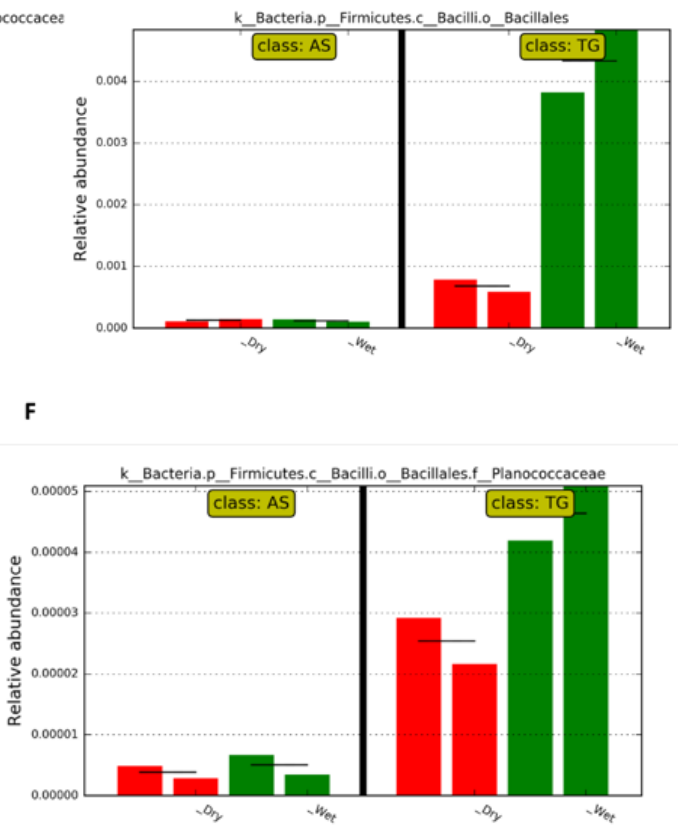

H

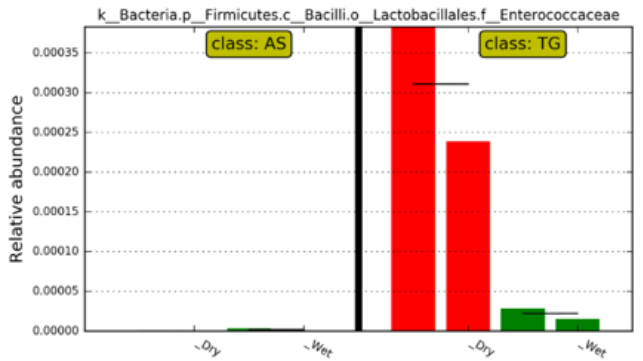


I

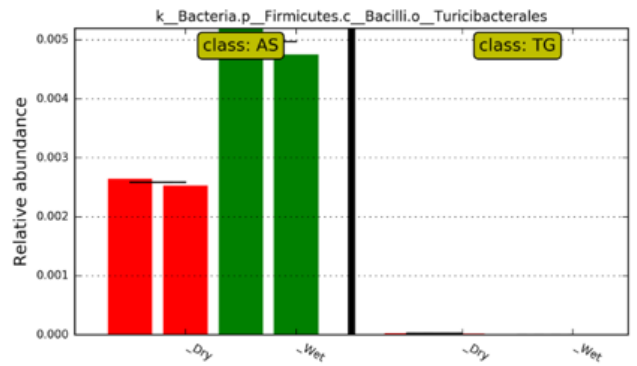

K

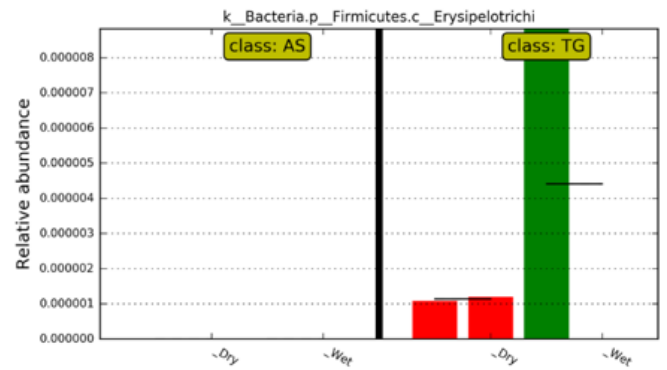

M

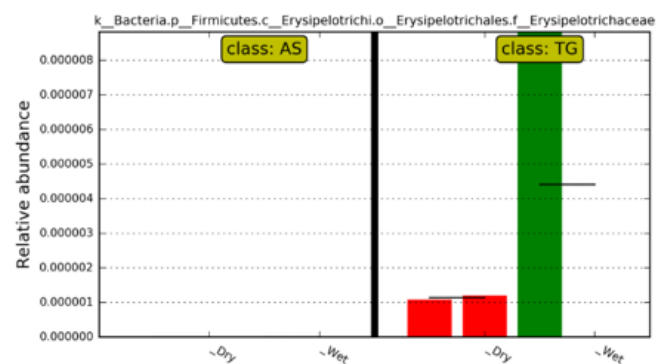

o

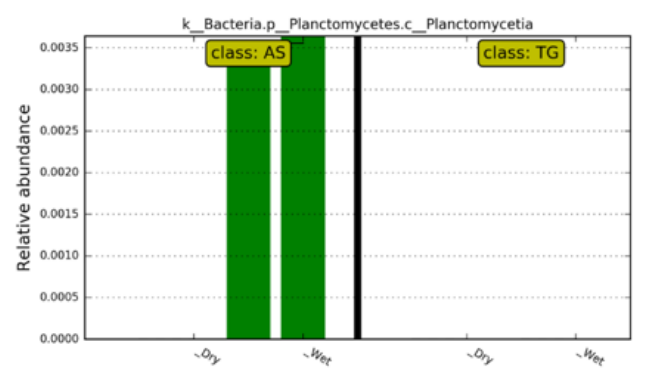

J
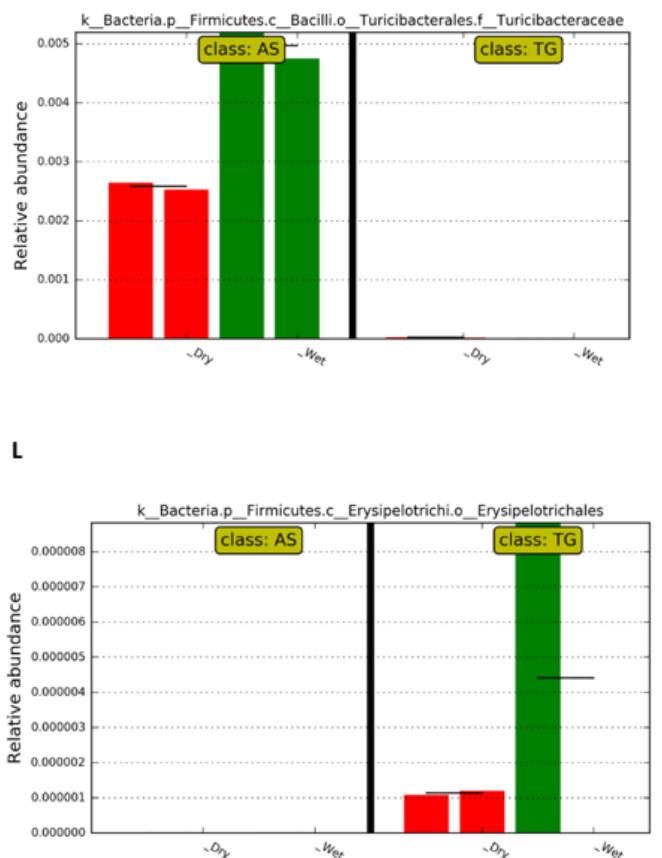

N
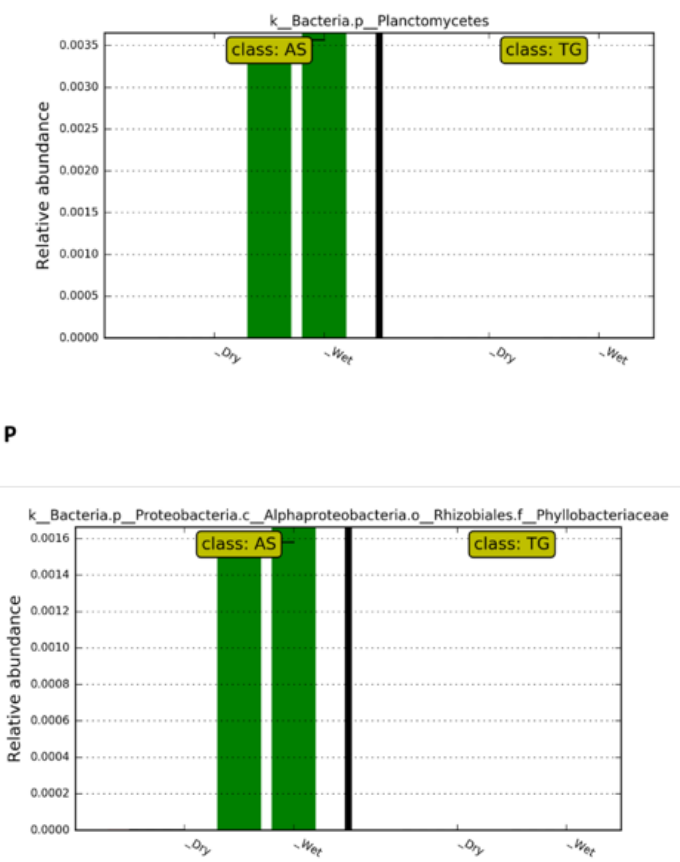


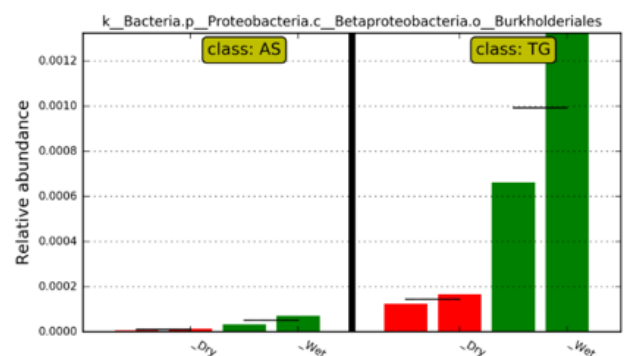

S

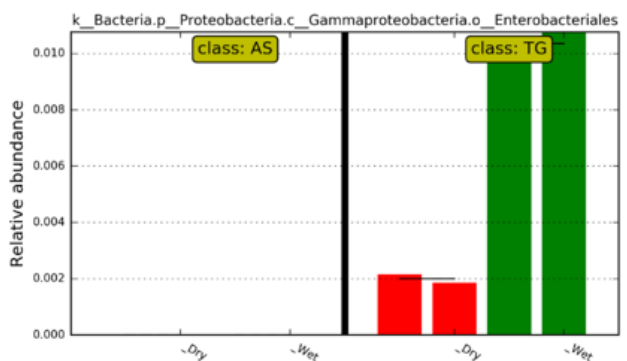

U

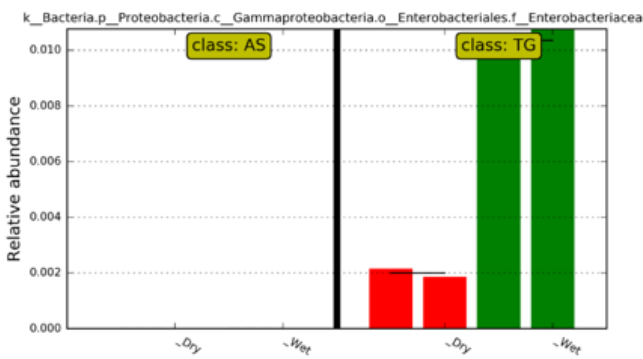

W

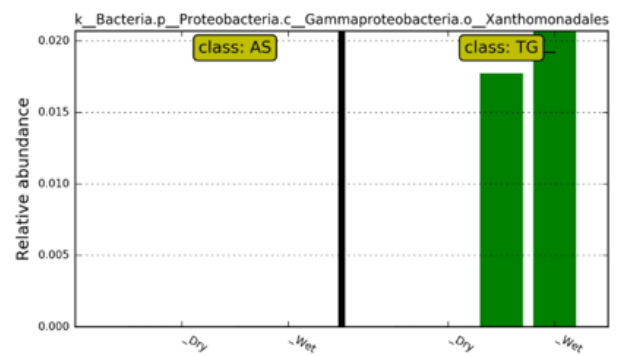

$\mathbf{R}$
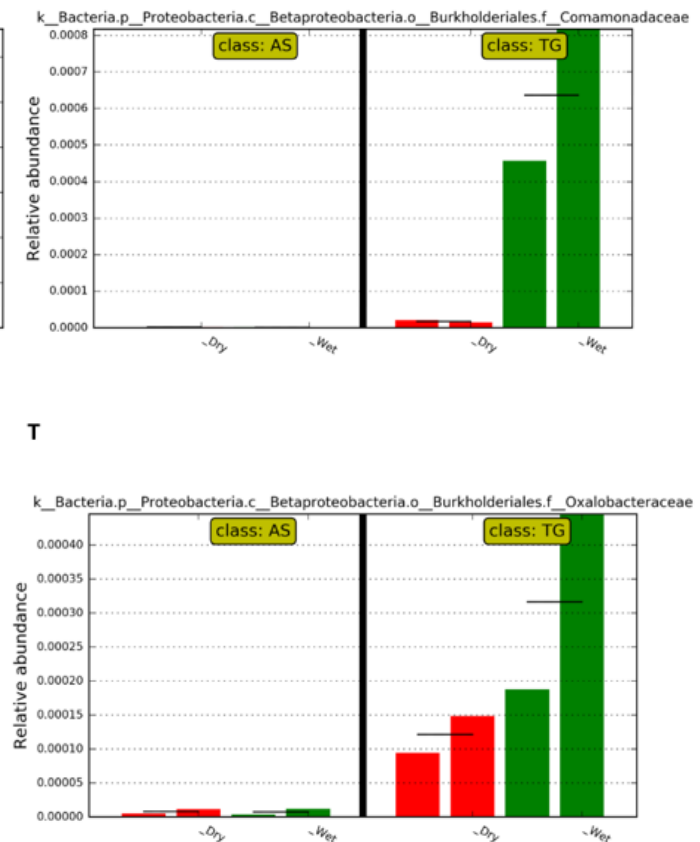

V

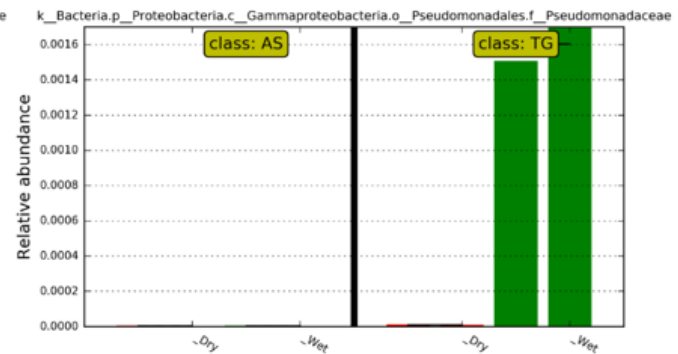

$\mathbf{X}$

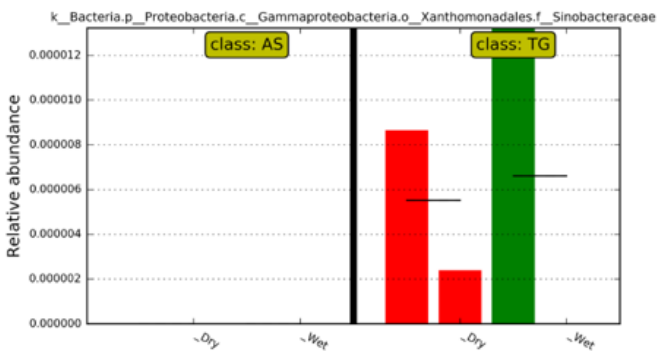




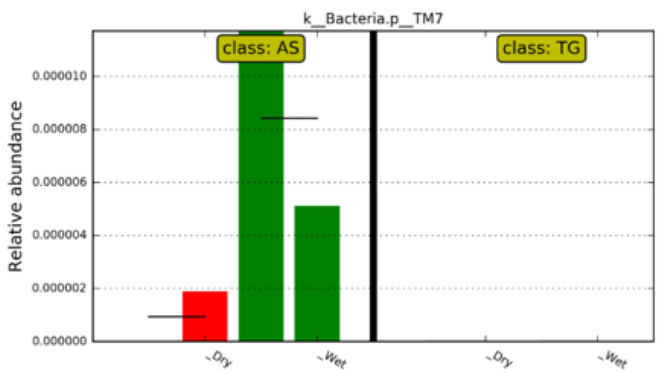

Figure 4. Differentially abundant bacterial clades detected by LEfSe, (A) Synechococcales, (B) Synechococcophycideae, (C) Synechococcacea, (D) Bacillales, (E) Staphylococcaceae, (F) Planococcaceae, (G) Lactobacillales, (H) Enterococcaceae, (I) Turicibacterales, (J) Turicibacteraceae, (K) Erysipelotrichi, (L) Erysipelotrichales, (M) Erysipelotrichaceae, (N) Plantomycetes, (O) Plantomycetia, (P) Phyllobacteriaceae, (Q) Burkholderiales, (R) Comamonadaceae, (S) Enterobacteriales, (T) Oxalobacteraceae, (U) Enterobacteriaceae, (V) Pseudomonaceae, (W) Xanthomonadales, (X) Sinobacteraceae, and (Y) TM7 among Asian seabass and tiger grouper samples in dry and wet seasons

[Note. AS are intestinal samples from Asian seabass; TG are intestinal samples from tiger grouper]

\section{Functional Profiles of Microbiotas}

Functional genes of all samples were collapsed into three different levels of KEGG. Level 1 was predominated mainly by metabolism-encoding genes, followed by genes encoding genetic and environmental information processing (Figure 5A). Many genes sequences could not be identified; meanwhile, the lowest functional genes present were under the gene encoding for cellular responses, human diseases and organismal systems. All gene functions in KEGG level 1 were present abundantly in dry season in both tiger grouper and Asian seabass samples.

The KEGG level 2 had a high abundance of genes encoding amino acid, carbohydrate, energy and lipid metabolisms, and genes encoding the metabolism of cofactors and vitamins (Figure 5B). Genes encoding the membrane transport dominated the environmental processing functions, while the genetic information processing encoding for translation also one of abundance gene function. Uniquely, gene function for human disease; cancer was mostly found in sample of Asian seabass during wet season. Generally, most of the gene functions in level 2 were highly present during dry season.

SIMPER analysis revealed that in Asian seabass, K02003, and K02004, which encoded unidentified functional genes, were mostly abundant in the dry season and contributed towards the dissimilarity between the seasons by $61 \%$ and $50 \%$, respectively. This was followed by K03406, K09687, K01990, K09686, 
K02015, K03091, K07024, and K01448, which were higher in the dry than the wet season, with contribution ranged between $25 \%$ and $36 \%$ dissimilarity (Figure $6 \mathrm{~A}$ and Table 5A). Based on the metagenome contribution of KO (Table 6A), family of Peptostreptococcaceae was highly contributed to all KOs of Asian seabass $(15 \%-27 \%)$, while gene K03406 that encodes methyl-accepting chemotaxis protein was associated abundantly with the genus of Vibrio at 19\%. All associated taxa were found abundantly in Asian seabass during the dry season.

In the tiger grouper, all KOs were found abundantly in the dry season, with the highest KOs from unidentified functions of K02003 and K02004 (76\% and $60 \%$ ) (Figure 6B). The remaining KOs, K06147, K09687, K01990, K03091, K00936, K09686, K07024, and K03088, contributed to dissimilarity at the rate of between $33 \%$ and $46 \%$ (Table 5B). Family Peptostreptococcaceae was dominant in KOs of tiger grouper ( $8 \%$ - 14\%), while genes K06147 and K03088 were highly influenced by family Clostridiaceae with contributions of $11 \%$ and $17 \%$, respectively (Table 6B). All taxa and associated genes were found abundantly throughout the dry season.

A

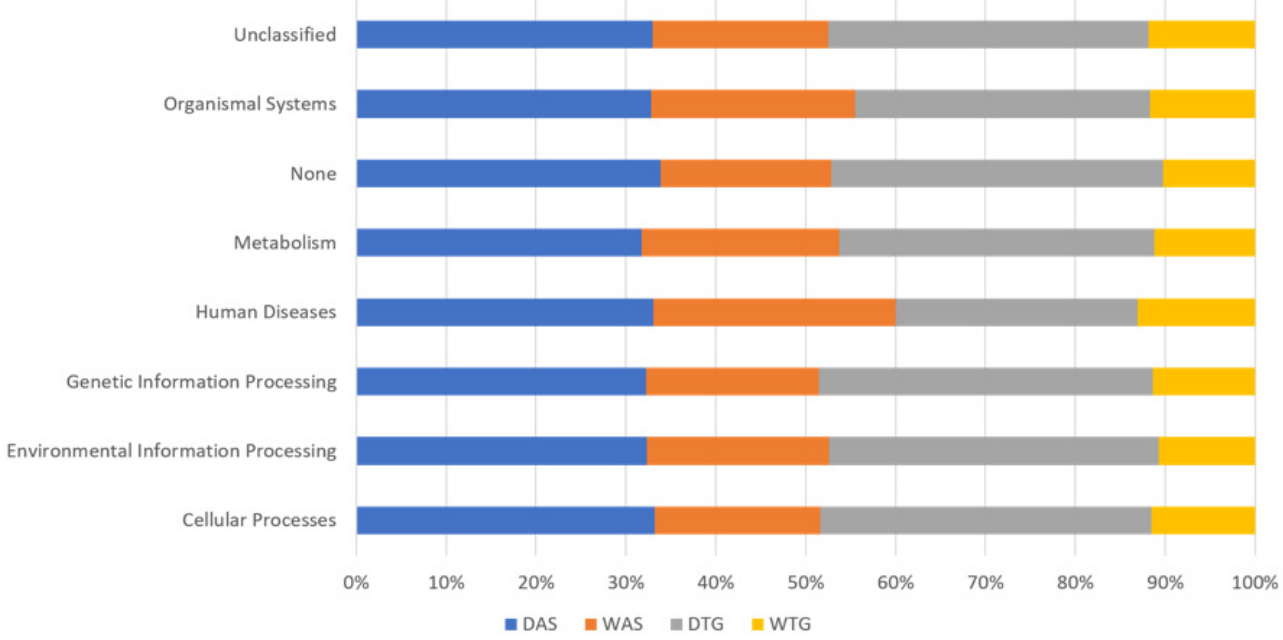



Human Diseases; Cancers Environmental Information Processing; Signaling Molecules and.. Cellular Processes; Transport and Catabolism Organismal Systems; Endocrine System Metabolism; Biosynthesis of Other Secondary Metabolites Genetic Information Processing; Transcription Cellular Processes; Cell Motility Metabolism; Xenobiotics Biodegradation and Metabolism Metabolism; Metabolism of Cofactors and Vitamins Metabolism; Energy Metabolism Metabolism; Lipid Metabolism Unclassified; Poorly Characterized Metabolism; Metabolism of Terpenoids and Polyketides Metabolism; Glycan Biosynthesis and Metabolism Metabolism; Carbohydrate Metabolism Metabolism; Amino Acid Metabolism

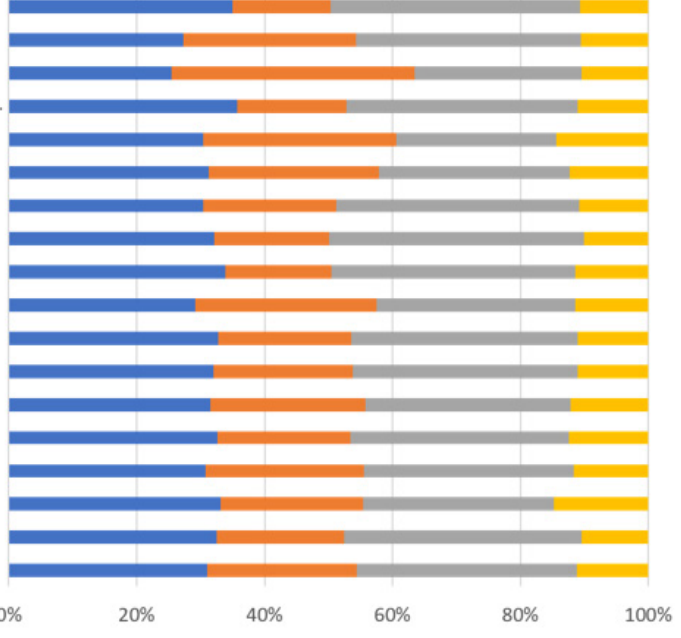

-DAS $=$ WAS $=$ DTG $=$ WTG

Figure 5. Abundance of genes categorized by functions based on (A) KEGG level 1 and (B) KEGG level 2

[Note. DAS are intestinal samples from Asian seabass for dry season; WAS are intestinal samples from Asian seabass for wet season; DTG are intestinal samples from tiger grouper for dry season; WTG are intestinal samples from tiger grouper for wet season; DW are water samples for dry season; WW are water samples for wet season]

A

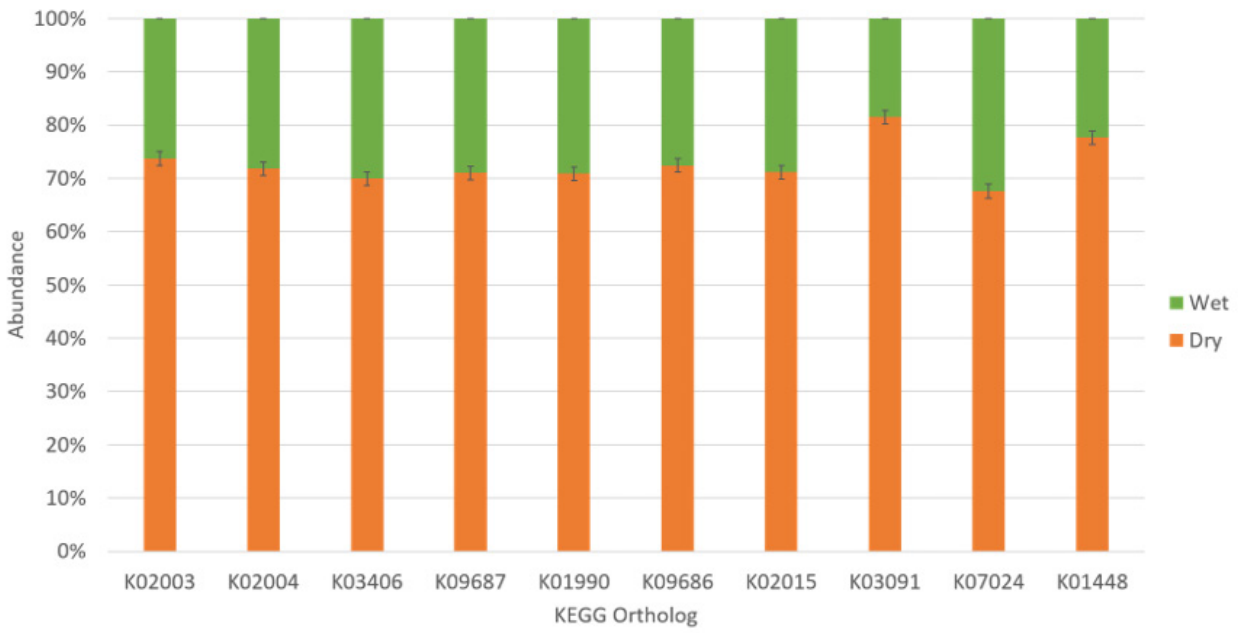


B

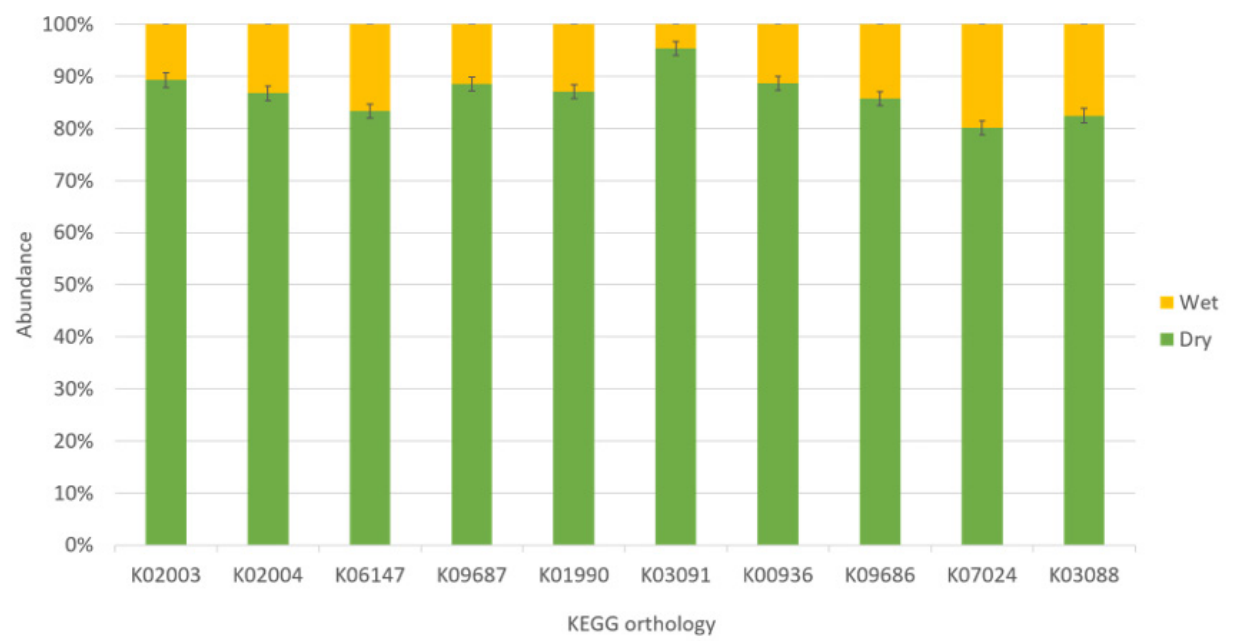

Figure 6. Top 10 of distinct KEGG orthologs in (A) Asian seabass and (B) tiger grouper samples between dry and wet seasons

Table 5

SIMPER analysis of contributions towards the dissimilarity of (A) Asian seabass and (B) tiger grouper samples in comparison between dry and wet seasons

\begin{tabular}{llcc}
\hline (A) KO & KEGG Description & $\begin{array}{c}\text { Average } \\
\text { dissimilarity }\end{array}$ & $\begin{array}{c}\text { Contribution } \\
(\%)\end{array}$ \\
\hline K02003 & None & 0.218 & 61 \\
K02004 & None & 0.176 & 50 \\
K03406 & Methyl-accepting chemotaxis protein & 0.129 & 36 \\
K09687 & $\begin{array}{l}\text { Antibiotic transport system ATP-binding } \\
\text { protein }\end{array}$ & 0.107 & 30 \\
K01990 & $\begin{array}{l}\text { ABC-2 type transport system ATP- } \\
\text { binding protein }\end{array}$ & 0.103 & 29 \\
K09686 & $\begin{array}{l}\text { Antibiotic transport system permease } \\
\text { protein }\end{array}$ & 0.100 & 28 \\
K02015 & $\begin{array}{l}\text { Iron complex transport system permease } \\
\text { protein }\end{array}$ & 0.100 & 28 \\
K03091 & $\begin{array}{l}\text { RNA polymerase sporulation-specific } \\
\text { sigma factor }\end{array}$ & 0.099 & 28 \\
K07024 & $\begin{array}{l}\text { None } \\
\text { K01448 }\end{array}$ & $\begin{array}{l}\text { N-acetylmuramoyl-L-alanine amidase } \\
\text { [EC:3.5.1.28] }\end{array}$ & 0.098 \\
\hline
\end{tabular}


Table 5 (Continued)

\begin{tabular}{llcc}
\hline (B) KO & KEGG Description & $\begin{array}{c}\text { Average } \\
\text { dissimilarity }\end{array}$ & $\begin{array}{c}\text { Contribution } \\
(\%)\end{array}$ \\
\hline K02003 & None & 0.481 & 76 \\
K02004 & None & 0.381 & 60 \\
K06147 & $\begin{array}{l}\text { ATP-binding cassette, subfamily B, } \\
\text { bacterial }\end{array}$ & 0.294 & 46 \\
K09687 & $\begin{array}{l}\text { Antibiotic transport system ATP- } \\
\text { binding protein }\end{array}$ & 0.284 & 45 \\
K01990 & $\begin{array}{l}\text { ABC-2 type transport system ATP- } \\
\text { binding protein }\end{array}$ & 0.260 & 41 \\
K03091 & $\begin{array}{l}\text { RNA polymerase sporulation-specific } \\
\text { K00936 }\end{array}$ & $\begin{array}{l}\text { None } \\
\text { K09686 }\end{array}$ & $\begin{array}{l}\text { Antibiotic transport system permease } \\
\text { protein }\end{array}$ \\
K07024 & None & 0.217 & 34 \\
K03088 & $\begin{array}{l}\text { RNA polymerase sigma-70 factor, ECF } \\
\text { subfamily }\end{array}$ & 0.212 & 33 \\
\hline
\end{tabular}

Table 6

Metagenome contribution of $K O$ with their associated taxa of $(A)$ Asian seabass and (B) tiger grouper samples in comparison between dry and wet seasons

\begin{tabular}{llccc}
\hline (A) KO & KEGG Description & Associated taxa & $\begin{array}{c}\text { Taxa } \\
\text { contribution (\%) }\end{array}$ & $\begin{array}{c}\text { Sample } \\
\text { group }\end{array}$ \\
\hline K02003 & None & Peptostreptococcaceae & 27.0 & DAS \\
K02004 & None & Peptostreptococcaceae & 24.0 & DAS \\
K03406 & $\begin{array}{l}\text { Methyl-accepting } \\
\text { chemotaxis protein }\end{array}$ & \multicolumn{1}{c}{ Vibrio } & 19.0 & DAS \\
K09687 & $\begin{array}{l}\text { Antibiotic transport } \\
\text { system ATP-binding } \\
\text { protein }\end{array}$ & Peptostreptococcaceae & 25.0 & DAS \\
K01990 & $\begin{array}{l}\text { ABC-2 type transport } \\
\text { system ATP-binding } \\
\text { protein }\end{array}$ & Peptostreptococcaceae & 27.0 & DAS \\
K09686 & $\begin{array}{l}\text { Antibiotic transport } \\
\text { system permease protein }\end{array}$ & Peptostreptococcaceae & 25.0 & DAS \\
K02015 & $\begin{array}{l}\text { Iron complex transport } \\
\text { system permease protein }\end{array}$ & Peptostreptococcaceae & 18.0 & DAS \\
\hline
\end{tabular}


Table 6 (Continued)

\begin{tabular}{|c|c|c|c|c|}
\hline (A) $\mathrm{KO}$ & KEGG Description & Associated taxa & $\begin{array}{c}\text { Taxa } \\
\text { contribution (\%) }\end{array}$ & $\begin{array}{l}\text { Sample } \\
\text { group }\end{array}$ \\
\hline K03091 & $\begin{array}{l}\text { RNA polymerase } \\
\text { sporulation-specific } \\
\text { sigma factor }\end{array}$ & Peptostreptococcaceae & 27.0 & DAS \\
\hline K07024 & None & Peptostreptococcaceae & 15.0 & DAS \\
\hline K01448 & $\begin{array}{l}\mathrm{N} \text {-acetylmuramoyl- } \\
\text { L-alanine amidase } \\
{[\mathrm{EC}: 3.5 .1 .28]}\end{array}$ & Peptostreptococcaceae & 27.0 & DAS \\
\hline (B) $\mathrm{KO}$ & KEGG Description & Associated taxa & $\begin{array}{c}\text { Taxa } \\
\text { contribution (\%) }\end{array}$ & $\begin{array}{l}\text { Sample } \\
\text { group }\end{array}$ \\
\hline K02003 & None & Peptostreptococcaceae & 14.0 & DTG \\
\hline K02004 & None & Peptostreptococcaceae & 13.0 & DTG \\
\hline K06147 & $\begin{array}{l}\text { ATP-binding cassette, } \\
\text { subfamily B, bacterial }\end{array}$ & Clostridiaceae & 11.0 & DTG \\
\hline K09687 & $\begin{array}{l}\text { Antibiotic transport } \\
\text { system ATP-binding } \\
\text { protein }\end{array}$ & Peptostreptococcaceae & 12.0 & DTG \\
\hline K01990 & $\begin{array}{l}\text { ABC-2 type transport } \\
\text { system ATP-binding } \\
\text { protein }\end{array}$ & Peptostreptococcaceae & 13.0 & DTG \\
\hline K03091 & $\begin{array}{l}\text { RNA polymerase } \\
\text { sporulation-specific } \\
\text { sigma factor }\end{array}$ & Peptostreptococcaceae & 13.0 & DTG \\
\hline K00936 & None & Peptostreptococcaceae & 11.0 & DTG \\
\hline K09686 & $\begin{array}{l}\text { Antibiotic transport } \\
\text { system permease } \\
\text { protein }\end{array}$ & Peptostreptococcaceae & 14.0 & DTG \\
\hline K07024 & None & Peptostreptococcaceae & 8.0 & DTG \\
\hline K03088 & $\begin{array}{l}\text { RNA polymerase } \\
\text { sigma- } 70 \text { factor, ECF } \\
\text { subfamily }\end{array}$ & Clostridiaceae & 17.0 & DTG \\
\hline
\end{tabular}

\section{DISCUSSION}

In this study, the alpha diversity indices demonstrated that bacterial communities in the intestinal samples of tiger grouper and Asian seabass that were reared in a semi-closed tropical marine fish hatchery were greatly influenced by seasons and was significantly higher in the dry season. Therefore, there was a microbiome shift according to the seasons in the hatchery. Overall, the fish intestinal microbiome in 
this study was dominated by the phylum of Proteobacteria, Firmicutes, Fusobacteria, and Plantomycetes, and the order of Clostridiales, Vibrionales, Fusobacteriales, Lactobacillales, and Rhodobacterales, as reported in previous studies (Dehler et al., 2017a, 2017b; Huang et al., 2017; Hennersdorf et al., 2016; Sullam et al., 2012).

Both dry and wet seasons share the same dominant phyla in the intestinal microbiome of Asian seabass, which were Proteobacteria, Firmicutes and Fusobacteria, but they were more abundant in the dry season, when water temperature, ambient temperature, and salinity were significantly higher. Indeed, Vibrionales dominated the intestinal microbiota of Asian seabass in both seasons, but significantly higher in dry season, as reported in a previous study (Zarkasi et al., 2014). This proved that Vibrio is a normal flora in the fish intestine and marine water, but also possible to cause vibriosis in cultured fish kept in high water temperature of the dry season (Abdullah et al., 2017; Mohamad et al., 2019c). Although there was no vibriosis outbreak in the period of this study period, it was suspected that further increase in the abundance of Vibrio might trigger an outbreak in the hatchery if no precaution was taken. During the wet season, Rhodobacterales and Lactobacillales were highly dominant, and the increasing trend of these bacteria had been related to low water temperature (Dang et al., 2008) and high occurrence of lactic acid bacteria that indicate healthy fish gut (Alonso et al., 2019), respectively.
On the other hand, intestinal microbiome of tiger grouper showed that Firmicutes was dominant during dry season, but low in wet season. Meanwhile, Proteobacteria was dominant during wet season, but low in dry season. This microbiome shift suggests that Gram-positive bacteria prefer dry weather condition, while Gram-negative bacteria showed favour towards wet weather condition. In dry season, tiger groupers were highly dominated by Clostridiales, which is similar to the microbiome of bluegill (Lepomis macrochirus) during late summer and fall (Ray, 2016). The diversity of bacteria during wet season was also more diverse compared to the dry season, which was believed to be correlated with the decrease of $\mathrm{pH}$ and salinity (Roquigny et al., 2020). Unlike Asian seabass, the raising water temperature seemed to inhibit the proliferation of Vibrionales in tiger grouper. Absence of disease outbreak during this study might suggest that there is equilibrium between pathogenic bacteria with the normal bacterial flora communities.

Comparative LEfSe analysis revealed the potential taxa biomarkers based on seasons. In tiger grouper, order Enterobacteriales was present abundantly, and it is capable of reducing nitrate to nitrite thus, is widely used in numerous applications including biocontrol in agriculture, control of infectious diseases, anticancer agents, and bioremediation (Octavia \& Lan, 2014). They were found in the wet season, when the nitrate level was abundant. Staphylococcaceae is one of the members of Bacillales order which is 
abundant during wet season. This bacterial family was mainly present on the skin and mucous membranes of animals, but their pathogenicity and infection mechanism (genera Staphylococcus) were considered threats due to its resistance towards antibiotics (Naimi et al., 2003). Abundant of this family during wet season showed that they favoured wet condition when water temperature and salinity were lower, while further drop in temperature might increase these bacterial abundances that can lead to foodborne disease due to microbial contamination. Order Lactobacillales was the members of lactic acid bacteria that produce lactic acid at the end of the carbohydrate metabolism and commonly used as probiotics in aquaculture (Walter, 2008). Higher abundance of these bacteria in the tiger grouper's gut suggests that wet season might trigger their abundance, thus stimulating immune response and improving disease resistance in the fish. Moreover, recently Gao et al. (2020) reported that class Erysipelotrichi, order Erysipelotrichales and family Erysipelotrichaeae were one of the newest microbes in gut of carnivorous fish. Only Enterococcaceae was found abundant in dry season and this bacterial taxon is a common inhabitant in the gastrointestinal tract of marine fish (Dehler et al., 2017a, $2017 b)$. This proved that the intestinal microbiota of fish, especially tiger grouper was affected by the seasonal changes. In Asian seabass, Synechococcaceae was the only taxon that differentiated dry and wet season, where this taxon mainly found during dry season. Most of the potential taxa biomarker from tiger grouper and Asian seabass were influenced by the physicochemical parameters, which suggested that the intestinal microbiome of the fish was associated with the water quality too.

Analysis on microbial functional genes revealed that the genes were mainly associated with metabolism, genetic and environmental information processing, and membrane transport, similar to the previous studies (Abia et al., 2018; P. Huang et al., 2018). Methyl-accepting chemotaxis protein (MCP) (K03406) was present in Asian seabass, and was associated with the genus Vibrio, which is known for its pathogenicity and disease outbreaks (Amalina et al., 2019; Mohamad et al., 2019a, 2019b). $\mathrm{MCP}$ is a sensory transducer that controls exopolysaccharides (EPS) production (Xu et al., 2011). In biofilms, EPS consists of polysaccharide, protein, and nucleic acid that provides structure and strength. Flowing water increases EPS production, resulting in overexpression of cell motility and bacterial chemotaxis (X. Zhang et al., 2019). K09687 and K01990 are closely related to the ABC-2 type transport system ATP-binding protein in antibiotic resistance gene, where these genes encode for $\mathrm{ABC}$ transporter protein (Fuellen et al., 2005). In Asian seabass and tiger grouper, most KOs were associated with family Peptostreptococcaceae, a member of allochthonous and autochthonous microbiota and anaerobic bacteria (Ringø et al., 1995). It showed higher contribution during dry season, indicating that the family Peptostreptococcaceae was a natural 
part of the intestinal microbiota in Asian seabass and tiger grouper that contribute in regulating internal process of fish species in dry season.

Dissimilar gene contribution in tiger grouper was dominated by environmental information processing ( $\mathrm{Qu}$ et al., 2008), which is important to fish and ecosystem health (X. Zhang et al., 2019). Thus, family Clostridiaceae was abundant in the healthy fish (de Bruijn et al., 2018) and the presence of marker genes associated with taxa Clostridiaceae throughout the dry season indicates that the tiger grouper was in healthy condition in the dry season. In general, gene functions in Asian seabass and tiger grouper were relatively higher during dry season, which indicate that dry season has more effect on the expression of the gene and supports the finding of dissimilar gene contribution where most of the taxa associated with the KOs were originated in the dry seasons.

\section{CONCLUSION}

In this study, the intestinal microbiota of tiger grouper and Asian seabass were influenced by dry and wet season in this semi-closed tropical marine fish hatchery. Moreover, it also showed that amplicon metagenomics analysis could provide useful data to predict and control possible bacterial disease outbreaks in the hatchery based on the intestinal microbiota of the fish. It is recommended for future study to increase the sample size for metagenomics analyses, while the investigation on unclassified taxa and its function in this study should be conducted for more understanding of the fish intestinal microbiome.

\section{ACKNOWLEDGEMENTS}

This study was financially supported by the Ministry of Higher Education, Malaysia under the Transdisciplinary Research Grant Scheme (TRGS/1/2019/UPM/02/5).

\section{REFERENCES}

Abdullah, A., Ramli, R., Ridzuan, M. S. M., Murni, M., Hashim, S., Sudirwan, F., Abdullah, S. Z., Mansor, N. N., Amira, S., Saad, M. Z., \& Amal, M. N. A. (2017). The presence of Vibrionaceae, Betanodavirus and Iridovirus in marine cage-cultured fish: Role of fish size, water physicochemical parameters and relationships among the pathogens. Aquaculture Reports, 7, 57-65. https://doi.org/10.1016/j. aqrep.2017.06.001

Abia, A. L. K., Alisoltani, A., Keshri, J., \& UbombaJaswa, E. (2018). Metagenomic analysis of the bacterial communities and their functional profiles in water and sediments of the Apies River, South Africa, as a function of land use. Science of the Total Environment, 616-617, 326-334. https:// doi.org/10.1016/j.scitotenv.2017.10.322

Ahmad, A. K., Amal, M. N. A., Saad, M. Z., Murni, M., Abdullah, A., Mustafa, S., \& Yusof, N. H. N. (2019). Prevalence, risk factors and transmission of Nervous Necrosis Virus in a hatchery producing hybrid grouper (Epinephelus lanceolatus $\times$ Epinephelus fuscoguttatus) fry. Pertanika Journal of Tropical Agricultural Science, 42(1), 125-138.

Alonso, S., Castro, M. C., Berdasco, M., de la Banda, I. G., Moreno-Ventas, X., \& de Rojas, A. H. (2019). Isolation and partial characterization of lactic acid bacteria from the gut microbiota of marine fishes for potential application as probiotics in aquaculture. Probiotics and 
Antimicrobial Proteins, 11(2), 569-579. https:// doi.org/10.1007/s12602-018-9439-2

Amal, M. N.A., Zamri-Saad, M., Zulkafli, A. R., Siti-Zahrah, A., Misri, S., Ramley, B., Shahidan, H., \& Sabri, M. Y. (2010). Water thermocline confirms susceptibility of tilapia cultured in lakes to Streptococcus agalactiae. Journal of Animal and Veterinary Advances, 9(22), 2811-2817. http://doi.org/10.3923/javaa.2010.2811.2817

Amalina, N. Z., Santha, S., Zulperi, D., Amal, M. N. A., Yusof, M. T., Zamri-Saad, M., \& InaSalwany, M. Y. (2019). Prevalence, antimicrobial susceptibility and plasmid profiling of Vibrio spp. isolated from cultured groupers in Peninsular Malaysia. BMC Microbiology, 19(1), 251. https:// doi.org/10.1186/s12866-019-1624-2

Barkham, T., Zadoks, R. N., Amal, M. N. A., Baker, S., Bich, V. T. N., Chalker, V., Chau, M. L., Dance, D., Deepak, R. N., van Doorn, H. R., Gutierrez, R. A., Holmes, M. A., Huong, L. N. P., Koh, T. H., Martins, E., Mehershahi, K., Newton, P., Ng, L. C., Phuoc, N. N. ... Chen, S. L. (2019). One hypervirulent clone, sequence type 283 , accounts for a large proportion of invasive Streptococcus agalactiae isolated from humans and diseased tilapia in Southeast Asia. PLoS Neglected Tropical Diseases, 13(6), e0007421. https://doi. org/10.1371/journal.pntd.0007421

Bray, J. R., \& Curtis, J. T. (1957). An ordination of the upland forest communities of southern Wisconsin. Ecology Monographs, 27(4), 325349. https://doi.org/10.2307/1942268

Dang, H., Li, T., Chen, M., \& Huang, G. (2008). Cross-ocean distribution of Rhodobacterales bacteria as primary surface colonizers in temperate coastal marine waters. Applied and Environmental Microbiology, 74(1), 52-60. https://doi.org/10.1128/AEM.01400-07

de Bruijn, I., Liu, Y., Wiegertjes, G. F., \& Raaijmakers, J. M. (2018). Exploring fish microbial communities to mitigate emerging diseases in aquaculture. FEMS Microbiology Ecology, 94(1), fix161. https://doi.org/10.1093/femsec/fix161

Debroas, D., Humbert, J. F., Enault, F., Bronner, G., Faubladier, M., \& Cornillot, E. (2009). Metagenomic approach studying the taxonomic and functional diversity of the bacterial community in a mesotrophic lake (Lac du Bourget - France). Environmental Microbiology, 11(9), 2412-2424. https://doi. org/10.1111/j.1462-2920.2009.01969.x

Dehler, C. E., Secombes, C. J., \& Martin, S. A. (2017a). Environmental and physiological factors shape the gut microbiota of Atlantic salmon parr (Salmo salar L.). Aquaculture, 467, 149-157. https://doi. org/10.1016/j.aquaculture.2016.07.017

Dehler, C. E., Secombes, C. J., \& Martin, S. A. (2017b). Seawater transfer alters the intestinal microbiota profiles of Atlantic salmon (Salmo salar L.). Scientific Reports, 7, 13877. https:// doi.org/10.1038/s41598-017-13249-8

Di Maiuta, N., Schwarzentruber, P., Schenker, M., \& Schoelkopf, J. (2013). Microbial population dynamics in the faeces of wood-eating loricariid catfishes. Letters in Applied Microbiology, 56(6), 401-407. https://doi.org/10.1111/lam.12061

Edgar, R. C., Haas, B. J., Clemente, J. C., Quince, C., \& Knight, R. (2011). UCHIME improves sensitivity and speed of chimera detection. Bioinformatics, 27(16), 2194-2200. https://doi.org/10.1093/bioinformatics/btr381

Fuellen, G., Spitzer, M., Cullen, P., \& Lorkowski, S. (2005). Correspondence of function and phylogeny of $\mathrm{ABC}$ proteins based on an automated analysis of 20 model protein data sets. Proteins, 61(4), 888-899. https://doi. org/10.1002/prot.20616

Gao, Y. M., Zou, K. S., Zhou, L., Huang, X. D., Li, Y. Y., Gao, X. Y., \& Zhang, X. Y. (2020). Deep insights into gut microbiota in four carnivorous coral reef fishes from the South 
China Sea. Microorganisms, 8(3), 426. https:// doi.org/10.3390/microorganisms8030426

Givens, C. E., Ransom, B., Bano, N., \& Hollibaugh, J. T. (2015). Comparison of the gut microbiomes of 12 bony fish and 3 shark species. Marine Ecology Progress Series, 518, 209-223. https:// doi.org/10.3354/meps 11034

Haas, B. J., Gevers, D., Earl, A. M., Feldgarden, M., Ward, D. V., Giannoukos, G., Ciulla, D., Tabbaa, D., Highlander, S. K., Sodergren, E., Methe, B., DeSantis, T. Z., The Human Microbiome Consortium, H. M., Petrosino, J. F., Knight, R., \& Birren, B. W. (2011). Chimeric 16S rRNA sequence formation and detection in sanger and 454-pyrosequenced PCR amplicons. Genome Research, 21(3), 494-504. https://doi.org/10.1101/gr.112730.110

Hammer, Ø., Harper, D. A. T., \& Ryan, P. D. (2001). PAST: Paleontological Statistics Software Package for Education and Data Analysis. Palaeontologia Electronica, 4(1), 1-9.

Hennersdorf, P., Mrotzek, G., Abdul-Aziz, M. A., \& Saluz, H. P. (2016). Metagenomic analysis between free-living and cultured Epinephelus fuscoguttatus under different environmental conditions in Indonesian waters. Marine Pollution Bulletin, 110(2), 726-734. https://doi. org/10.1016/j.marpolbul.2016.05.009

Hewson, I., Paerl, R. W., Tripp, H. J., Zehr, J. P., \& Karl, D. M. (2009). Metagenomic potential of microbial assemblages in the surface waters of the central Pacific Ocean tracks variability in oceanic habitat. Limnology and Oceanography, 54(6), 1981-1994. https://doi. org/10.4319/1o.2009.54.6.1981

Huang, F., Pan, L., Lv, N., \& Tang, X. (2017). Characterization of novel Bacillus strain N31 from mariculture water capable of halophilic heterotrophic nitrification-aerobic denitrification. Journal of Bioscience and
Bioengineering, 124(5), 564-571. https://doi. org/10.1016/j.jbiosc.2017.06.008

Huang, P., Zhang, Y., Xiao, K., Jiang, F., Wang, H., Tang, D., \& Liu, H. (2018). The chicken gut metagenome and the modulatory effects of plant-derived benzylisoquinoline alkaloids. Microbiome, 6, 211. https://doi. org/10.1186/s40168-018-0590-5

Ismail, M. S., Syafiq, M. R., Siti-Zahrah, A., Fahmi, S., Shahidan, H., Hanan, Y., Amal, M. N. A., \& Zamri-Saad, M. (2017). The effect of feed-based vaccination on tilapia farm endemic for streptococcosis. Fish and Shellfish Immunology, 60, 21-24. https://doi.org/10.1016/j. fsi.2016.11.040

Klindworth, A., Pruesse, E., Schweer, T., Peplies, J., Quast, C., Horn, M., \& Glöckner, F. O. (2013). Evaluation of general 16S ribosomal RNA gene PCR primers for classical and next-generation sequencing-based diversity studies. Nucleic Acids Research, 41(1), e1. https://doi.org/10.1093/nar/gks808

Langille, M. G., Zaneveld, J., Caporaso, J. G., McDonald, D., Knights, D., Reyes, J. A., \& Beiko, R. G. (2013). Predictive functional profiling of microbial communities using 16S rRNA marker gene sequences. Nature Biotechnology, 31(9), 814-821. https://doi. org/10.1038/nbt.2676

Little, D. C., Newton, R. W., \& Beveridge, M. C. M. (2016). Aquaculture: A rapidly growing and significant source of sustainable food? Status, transitions and potential. Proceedings of the Nutrition Society, 75(3), 274-286. https://doi. org/10.1017/S0029665116000665

Lyons, P. P., Turnbull, J. F., Dawson, K. A., \& Crumlish, M. (2015). Exploring the microbial diversity of the distal intestinal lumen and mucosa of farmed rainbow trout Oncorhynchus mykiss (Walbaum) using next generation 
sequencing (NGS). Aquaculture Research, 48(1), 77-91. https://doi.org/10.1111/are.12863

Magoč, T., \& Salzberg, S. L. (2011). FLASH: Fast length adjustment of short reads to improve genome assemblies. Bioinformatics, 27(21), 2957-2963. https://doi.org/10.1093/ bioinformatics/btr507

Martínez-Porchas, M., \& Vargas-Albores, F. (2017). Microbial metagenomics in aquaculture: A potential tool for a deeper insight into the activity. Reviews in Aquaculture, 9(1), 42-56. https://doi.org/10.1111/raq.12102

Mohamad, N., Amal, M. N. A., Saad, M. Z., Yasin, I. S. M., Zulkiply, N. A., Mustafa, M., \& Nasruddin, N. S. (2019a). Virulence-associated genes and antibiotic resistance patterns of Vibrio spp. isolated from cultured marine fishes in Malaysia. BMC Veterinary Research, 15(1), 176. https://doi.org/10.1186/s12917-019-1907-8

Mohamad, N., Amal, M. N. A., Yasin, I. S. M., Saad, M. Z., Nasruddin, N. S., Al-saari, N., Mino. S., \& Sawabe, T. (2019b). Vibriosis in cultured marine fishes: A review. Aquaculture, 512, 734289. https://doi.org/10.1016/j. aquaculture.2019.734289

Mohamad, N., Mustafa, M., Amal, M. N. A., Saad, M. Z., Md Yasin, I. S., \& Al-saari, N. (2019c). Environmental factors associated with the presence of Vibrionaceae in tropical cagecultured marine fishes. Journal of Aquatic Animal Health, 31(2), 154-167. https://doi. org/10.1002/aah.10062

Naimi, T. S., LeDell, K. H., Como-Sabetti, K., Borchardt, S. M., Boxrud, D. J., Etienne, J., \& Danila, R. N. (2003). Comparison of communityand health care-associated methicillin-resistant Staphylococcus aureus infection. Journal of the American Medical Association, 290(22), 2976298. https://doi.org/10.1001/jama.290.22.2976

Octavia, S., \& Lan, R. (2014). The family Enterobacteriaceae. In E. Rosenberg, E.
F. DeLong, S. Lory, E. Stackebrandt, \& F. Thompson (Eds.), The prokaryotes (pp. 223286). Springer. https://doi.org/10.1007/978-3642-38922-1_167

Othman, M. F., Hashim, M., Eim, Y. M., Amal, M. N. A., Ikhsan, N., Chong, H. G., \& Merican, Z. (2017). Transforming the aquaculture industry in Malaysia. World Aquaculture, 48(2), 16-23.

Qu, A., Brulc, J. M., Wilson, M. K., Law, B. F., Theoret, J. R., Joens, L. A., \& Nelson, K. E. (2008). Comparative metagenomics reveals host specific metavirulomes and horizontal gene transfer elements in the chicken cecum microbiome. PLOS One, 3(8), e2945. https://doi. org/10.1371/journal.pone.0002945

Ray, C. (2016). Characterization of the gut and skin microbiomes of wild-caught fishes from Lake Guntersville, Alabama [Master's thesis, Auburn University]. Auburn University Electronic Theses and Dissertations. https://etd.auburn.edu/ handle/10415/5314

Ringø, E., Strøm, E., \& Tabachek, J. A. (1995). Intestinal microflora of salmonids: A review. Aquaculture Research, 26(10), 773789. https://doi.org/10.1111/j.1365-2109.1995. tb00870.x

Roeselers, G., Mittge, E. K., Stephens, W. Z., Parichy, D. M., Cavanaugh, C. M., Guillemin, K., \& Rawls, J. F. (2011). Evidence for a core gut microbiota in the zebrafish. The ISME Journal, 5(10), 1595-1608. https://doi.org/10.1038/ ismej. 2011.38

Roquigny, R., Mougin, J., Le Bris, C., BonninJusserand, M., Doyen, P., \& Grard, T. (2020). Characterization of the marine aquaculture microbiome: A seasonal survey in a seabass farm. Aquaculture, 531, 735987. https://doi. org/10.1016/j.aquaculture.2020.735987

Segata, N., Izard, J., Waldron, L., Gevers, D., Miropolsky, L., Garrett, W. S., \& Huttenhower, C. (2011). Metagenomic biomarker discovery 
and explanation. Genome Biology, 12(6), 1-18. https://doi.org/10.1186/gb-2011-12-6-r60

Sullam, K. E., Essinger, S. D., Lozupone, C. A., O'connor, M. P., Rosen, G. L., Knight, R. O. B., \& Russell, J. A. (2012). Environmental and ecological factors that shape the gut bacterial communities of fish: A meta-analysis. Molecular Ecology, 21(13), 3363-3378. https://doi. org/10.1111/j.1365-294X.2012.05552.x

Tarnecki, A. M., Burgos, F. A., Ray, C. L., \& Arias, C. R. (2017). Fish intestinal microbiome: Diversity and symbiosis unravelled by metagenomics. Journal of Applied Microbiology, 123(1), 2-17. https:// doi.org/10.1111/jam.13415

Walter, J. (2008). Ecological role of lactobacilli in the gastrointestinal tract: Implications for fundamental and biomedical research. Applied and Environmental Microbiology, 74(16), 49854996. https://doi.org/10.1128/AEM.00753-08

Wang, L., Zhang, J., Li, H., Yang, H., Peng, C., Peng, Z., \& Lu, L. (2018). Shift in the microbial community composition of surface water and sediment along an urban river. Science of the Total Environment, 627, 600-612. https://doi. org/10.1016/j.scitotenv.2018.01.203

Wu, S., Gao, T., Zheng, Y., Wang, W., Cheng, Y., \& Wang, G. (2010). Microbial diversity of intestinal contents and mucus in yellow catfish (Pelteobagrus fulvidraco). Aquaculture, 303(14), 1-7. https://doi.org/10.1016/j. aquaculture.2009.12.025

Wu, S., Wang, G., Angert, E. R., Wang, W., Li, W., \& Zou, H. (2012). Composition, diversity, and origin of the bacterial community in grass carp intestine. PLOS One, 7(2), e30440. https://doi. org/10.1371/journal.pone. 0030440
Xu, Q., Black, W. P., Nascimi, H. M., \& Yang, Z. (2011). DifA, a methyl-accepting chemoreceptor protein-like sensory protein, uses a novel signaling mechanism to regulate exopolysaccharide production in Myxococcus xanthus. Journal of Bacteriology, 193(3), 759767. https://doi.org/10.1128/JB.00944-10

Zarkasi, K. Z., Abell, G. C., Taylor, R. S., Neuman, C., Hatje, E., Tamplin, M. L., \& Bowman, J. P. (2014). Pyrosequencing-based characterization of gastrointestinal bacteria of Atlantic salmon (Salmo salar L.) within a commercial mariculture system. Journal of Applied Microbiology, 117(1), 18-27. https://doi.org/10.1111/jam.12514

Zhang, J., Kobert, K., Flouri, T., \& Stamatakis, A. (2013). PEAR: A fast and accurate Illumina Paired-End reAd mergeR. Bioinformatics, 30(5), 614-620. https://doi.org/10.1093/bioinformatics/ btt593

Zhang, M., Sun, Y., Liu, Y., Qiao, F., Chen, L., Liu, W. T., \& Li, E. (2016). Response of gut microbiota to salinity change in two euryhaline aquatic animals with reverse salinity preference. Aquaculture, 454, 72-80. https://doi. org/10.1016/j.aquaculture.2015.12.014

Zhang, X., Li, L., Butcher, J., Stintzi, A., \& Figeys, D. (2019). Advancing functional and translational microbiome research using meta-omics approaches. Microbiome, 7(1), 154. https://doi. org/10.1186/s40168-019-0767-6 
